\title{
Language Preference in Monolingual and Bilingual Infants
}

\author{
Ayasha Valji \\ School of Communication Sciences and Disorders \\ McGill University, Montreal
}

December, 2004

A thesis submitted to McGill University in partial fulfillment of the requirements of the degree of Master of Science in Speech-Language Pathology 


\section{Table of Contents}

Section

\section{Page Number}

Abstract...........................................3

Sommaire.........................................4

Acknowledgements...............................5

Introduction......................................6

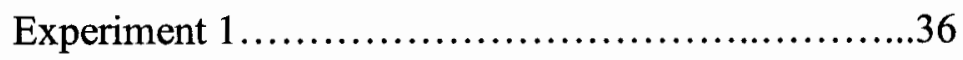

Methods......................................37

Results........................................44

Discussion..................................45

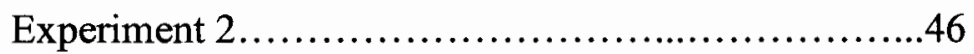

Methods.......................................46

Results.......................................47

Overall Discussion...................................51

References....................................61

Appendix A.....................................65

Appendix B.....................................66

Appendix C......................................69

Appendix D..................................... 75

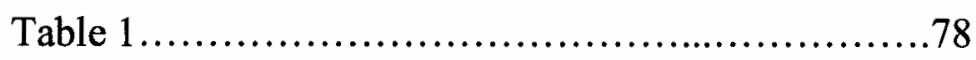

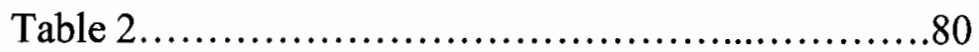

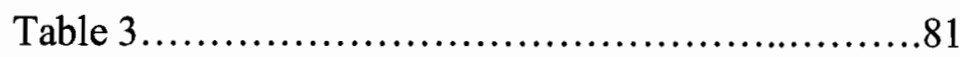




\begin{abstract}
Monolingual infants have been shown to discriminate rhythmically different languages and to prefer their native language over an unfamiliar language. Such research with bilingual infants is extremely limited, but is necessary to determine if the pattern and rate of bilingual language acquisition parallels that of monolingual babies. The present study addressed this issue by comparing language preference in monolingual English, monolingual French, and bilingual English/French infants at 6- and 9-months of age. Infants listened to passages produced by several female talkers in three rhythmically different languages (English, French, Japanese). Listening preference was measured using a sequential preferential looking procedure. Unexpectedly, monolingual infants did not demonstrate a native language preference; however, the bilingual 9-month-olds preferred their native languages over a non-native language. This finding indicates that bilingual infants attend to language variation differently from monolinguals. This selective attention may serve to facilitate the simultaneous acquisition of two languages.
\end{abstract}




\section{Sommaire}

Il a été démontré que les poupons monolingues font une discrimination rythmique de différentes langues et qu'ils préfèrent leur langue maternelle à une langue qui ne leur est pas familière. De telles recherches auprès d'enfants bilingues sont extrêmement limitées, mais il est nécessaire de déterminer si le mode et la fréquence d'acquisition simultanée de deux langues permettent de faire une parallèle avec la perception des enfants monolingues. La présente étude désire aborder cette problématique en comparant la préférence de langage chez les bébés monolingues anglophones, les bébés monolingues francophones, et les bébés bilingues (anglais/français) âgés de 6 mois et 9 mois. On présente aux poupons des extraits de discours émis par trois voix féminines dans trios langues aux rythmiques différentes (anglais, français, japonais). La préférence d'écoute fut mesurée par un procédé séquentiel d'attention préférentielle. Contrairement à ce qu'on pourrait s'attendre, les poupons monolingues ne démontrent pas une préférence pour leur langue maternelle; toutefois, les enfants bilingues âgés de 9 mois ont préféré leurs langues maternelles à la langue non familière. Ces résultats indiquent que les enfants bilingues perçoivent différemment les variations de langage. Cette attention sélective pourrait servir à faciliter l'acquisition simultanée de deux langues. 


\section{Acknowledgements}

First of all, I would like to thank my supervisor, Linda Polka, for all her help and guidance in designing and implementing this research from start to finish. In addition, I would like to thank the members of my thesis committee, Linda Polka, Fred Genesee, and Susan Rvachew for their valuable feedback. I would also like to thank my lab members, Eva Villalba, Monika Molnar, Georgina Hernandez, Rachel Carson, and Emily Rosales for their help with recruiting subjects and conducting some of the experiments. In particular, I would like to thank another lab member, Megha Sundara, for all her support and guidance. Thank you to my parents and brother who have always been a strong support in my life. Finally, I would like to thank my friends, Jennifer Cuffe, Bonita Squires, Christine Butt, Mandy Gaspar, Devin Hayward, and Byron Alley, for being there for me and putting up with me while I worked on this thesis. 
Language Preference in Monolingual and Bilingual Infants

The universal goal of language acquisition research is to build a comprehensive model capable of describing how children develop speech and language within the first few years of life. Such a model would be valuable as a means of comprehending linguistic and cognitive development, as a guide to parents and educators who are responsible for shaping children's language environment, and as a guide to clinicians who assess and treat children with speech and language difficulties. Unfortunately the majority of language acquisition research, and consequently the models of language development, focus on monolingual children. Considering that in most parts of the world children are raised with more than one language (Harris \& Nelson, 1992), an acceptable model of language acquisition must be capable of explaining various types of language acquisition. This need is clearly evident in Canada where ethnic, and hence linguistic, diversity is prevalent. Researchers are consequently beginning to recognise the strong need for bilingual language acquisition research in order to evaluate and build upon current monolingually-based models of language development.

Many researchers examine specific characteristics of monolingual language development in order to collectively develop models of language acquisition. One of these areas of specialization is speech perception research. Perhaps one of the most interesting findings within this field is that the specific language a child is raised with influences his/her perception of speech from the earliest stages of development. It has been observed that even at birth newborns are more attentive to their maternal language over a foreign language (Moon, Cooper, \& Fifer, 1993). In addition, research demonstrates that an infant's linguistic environment affects how the infant perceives consonants by 10-12 months of age (Werker \& Tees, 1984). Unfortunately, similar 
research examining speech perception abilities with bilingual children is virtually nonexistent; thus, numerous questions regarding bilingual language development remain unanswered. For instance, how does being raised with two languages affect the way that infants process speech? Does bilingual language development follow the same pattern and rate as monolingual language development? Do bilingual babies pay equal attention to both of their languages? And perhaps the most basic question: Do bilingual babies differentiate the two languages in their environment, and if so when and how? Evidently, research is needed to answer these questions. The purpose of this thesis is to initiate such investigations by comparing how monolingual and bilingual infants adapt their speech perception abilities when raised in varying linguistic environments. Specifically, I will investigate language preference with monolingual English, monolingual French, and bilingual English-French infants.

Many researchers have wondered when and how infants begin to distinguish different languages in their environment. The need for a bilingual child to be able to discriminate the languages in her/his environment is particularly important since s/he is learning about two languages with different underlying structures. If the child could not discriminate their two languages s/he would be lost when trying to comprehend the underlying structure of each language. Some researchers have begun this research by first examining whether monolingual infants are capable of discriminating different languages. It is thus possible to rely on the monolingual results as a starting point for considering possible patterns of bilingual development. Over the past 20 years, monolingual language discrimination has been studied by contrasting numerous languages, involving infants of varying language backgrounds, ranging in age from birth to twelve months, and utilising different stimulus sets and testing procedures. Several hypotheses describing the 
emergence of language discrimination and recognition have emerged from these experiments. A basic understanding of how languages differ in rhythmic structure is central to this research. For this reason, the literature review will begin with a brief discussion on this topic in which I will define relevant terms that emerge in the infant language discrimination and preference literature. I will then proceed by reviewing monolingual language discrimination research and the hypotheses that have been raised to explain existing findings. A discussion of these findings is organized developmentally with research on newborns presented first, followed by research on 2-month-olds, and then 4 and 5-month-olds are presented together. Following this, I will describe the very small number of studies that have investigated monolingual language preference, followed by the few studies that have examined language discrimination and preference in bilingual babies. Tables 1-3 provide a summary of this literature. Finally, I will discuss the rationale for my experiment.

\section{1) Language \& Rhythmic Classes}

People have often noted that different languages appear to possess different rhythmic properties. While the concept of rhythm seems rather intuitive, linguists define rhythm as the characteristic timing of a language. This is in contrast to prosody which is the intonation and pitch of a language. However, it should be noted that in this field the terms rhythm and prosody are often used interchangeably. Linguists have traditionally divided languages into three rhythmic classes: stress-timed, syllable-timed, and moratimed languages. According to this classification English and Dutch are stress-timed languages, French, Spanish, and Italian are syllable-timed languages, and Japanese is a mora-timed language. This classification system has been controversial for a few reasons: (a) acoustic properties that reflect the perceptual properties of rhythm have been 
difficult to obtain, (b) for some languages there is debate as to which category a language belongs (e.g., Catalan, Portuguese, and Polish), (c) some languages do not appear to fit into any of the three categories, and (d) many languages still remain to be classified. However, Ramus, Dupoux, and Mehler (2003) have recently conducted perceptual experiments that seem to provide a more empirical way of quantifying the perception of rhythm. Moreover, research in the area of speech segmentation has confirmed the perceptual reality of rhythmic classes by revealing that language rhythm influences the way adults process speech.

The segmentation problem investigates how children and adults parse speech into discrete words and sounds. For example, when native speakers of English hear the phrase "thecatiscrossingtheroad", they automatically insert word boundaries to make sense of the utterance, even though the acoustic information does not contain these boundaries. Although we take this ability for granted, identifying word boundaries is actually a difficult computational task. Cross-linguistic research has suggested that speakers of different languages use different strategies according to the rhythmic classes described above. For instance, it has been found that speakers of French, Italian, Spanish, Portuguese and Catalan segment speech into syllable-size units (Cutler, Mehler, Norris \& Segui, 1986; Pallier, Sebastian, Felguera, Christophe, \& Mehler, 1993; Sebastian, Dupoux, Seguf \& Mehler, 1992), speakers of English and Dutch segment speech into strong and weak syllables (Cutler et al., 1986), and Japanese and Tamil speakers segment speech into morae, a subsyllabic method of segmentation (Cutler \& Otake, 1994; Otake, Hatano, Cutler, Mehler, 1993). Thus, the concept of rhythmic class appears to influence how people process language. Rhythmic classes are also known as phonological classes. 
Languages from within the same rhythmic class are known as intraclass languages, while languages from different classes are known as interclass languages.

\section{2) Monolingual Language Discrimination}

\section{i) Newborns.}

There are only two published studies on language discrimination abilities with newborn infants (see Table 1 for a summary of monolingual language discrimination studies). Mehler and colleagues were the pioneering researchers in this field with their experiments in 1988 (Mehler et al.). In this study French-learning infants listened to sentences produced by a bilingual female speaker of either Russian/French or English/Italian in adult-directed speech. The High Amplitude Sucking (HAS) paradigm was utilized in this study. Infants were presented with samples of one language during a habituation phase and once a habituation criterion was reached, samples of the other language were presented in the test phase. An increase in sucking was expected if the infant noticed the language change. A control group who heard new samples of the same language during the test phase was compared to the experimental group to confirm that the increase was not due to spontaneous recovery. In the HAS procedure, the presentation of stimuli is typically infant-controlled, that is the stimuli are presented contingent upon the infants' high amplitude sucks (see Polka, Jusczyk, \& Rvachew, 1995; Werker et al, 1998). In the Mehler study, however, stimulus presentation was not infantcontrolled, instead infants were presented with samples of speech that were fixed in duration and sucking was measured as an index of the infant's interest in listening to the passages. Using this method, a series of experiments revealed that 4-day-old French babies could discriminate between French and Russian sentences, but could not discriminate between English and Italian sentences. It was also observed that a group of 
newborns for whom the primary language spoken at home was neither French nor Russian could not discriminate the French and Russian sentences. These researchers also tested French newborns on two modified versions of the above experiments. In one experiment, the French and Russian sentences were played backwards. This modification preserved the spectral content of the stimuli but the direction of spectral change was unlawful for the languages; thus reversing the stimuli disturbed the temporal or rhythmic organization. The French newborns failed to discriminate between the two languages in this condition. In another experiment, the French and Russian sentences were low-pass filtered, removing energy above $400 \mathrm{~Hz}$. This condition preserved the rhythmic structure while removing most of the segmental detail. In this condition, the French newborns could discriminate the two languages.

Based on the above findings Mehler and colleagues (1988) drew two conclusions. First, they concluded that newborn babies are able to discriminate languages when one of the languages is familiar to the infant. Second, they concluded that newborns rely on the rhythmic or prosodic information in the speech signal to make these language discriminations. In a later paper, Mehler, Dupoux, Nazzi, \& Dehaene-Lambertz (1996) proposed a more detailed model describing the information that newborns might access and use to discriminate languages. They proposed the Time Intensity Grid REpresentation model (TIGRE), stating that newborns discriminate languages using crude prosodic representations of sentences; that is, they attend to the duration and intensity of vowels and the characteristic rhythmic patterns of the language. Hence, according to the TIGRE model, rhythm plays a central role in the speech perception abilities of newborns and very young infants. 
Mehler and colleagues' (1988) conclusion that newborns can discriminate languages only when they are familiar with one of the languages remained unchallenged for some time. However, in 1994 Mehler and Christophe re-analyzed the data in this study. Their reanalysis revealed that the French newborns could in fact discriminate the two rhythmically-different foreign languages, English and Italian. This result revealed that newborns can discriminate language pairs that they have never heard. Since Italian and English are rhythmically different languages, this new result was in line with their claim that newborns are sensitive to rhythmic information. However, in their earlier interpretation, later referred to as the Native-language recognition hypothesis, infants were not expected to discriminate two foreign (unfamiliar) languages. Thus, following the data re-analysis, this view was no longer an adequate explanation for their findings.

Several hypotheses could potentially explain the findings of Mehler and colleagues (1988, 1994). Nazzi, Bertoncini and Mehler (1998) outlined three alternative hypotheses and collected data to test each hypothesis. The Native language recognition hypothesis ( $\mathrm{N}$ hypothesis) described above states that newborns recognize their own language and consequently are able to discriminate it from any other language. According to this hypothesis two foreign languages will not be discriminated by a newborn baby. The second hypothesis, the General language discrimination hypothesis (G hypothesis) states that infants are able to discriminate any pair of languages, regardless of familiarity. This theory could better explain the findings observed in the reanalysis conducted by Mehler and Christophe (1994) where it was discovered that the newborns could in fact discriminate two foreign languages. The third hypothesis, the Rhythm-based language discrimination hypothesis ( $\mathrm{R}$ hypothesis), claims that newborns are sensitive to the rhythm of languages and that the infants use rhythm to perform discriminations. 
According to this view, infants can discriminate rhythmically different languages (interclass languages), but not language that are rhythmically similar to each other (intraclass languages).

To test these hypotheses, Nazzi and colleagues (1998) conducted a series of language discrimination experiments with French-learning newborn babies. The infants listened to passages in English, Japanese, Dutch, Spanish, and Italian produced by four female monolingual speakers of each language. These passages were produced in an adult-directed speech style and were low-pass filtered. The HAS procedure was utilised in a habituation paradigm, however unlike the experiments conducted by Mehler and colleagues (1988), stimulus presentation in this study was contingent upon sucking behavior. In the first and second experiments, the French newborns listened to an English/Japanese contrast and an English/Dutch contrast. According to the $\mathrm{N}$ hypothesis, the newborns should not discriminate either contrast, whereas both contrasts would be possible according to the $\mathrm{G}$ hypothesis. The results supported the rhythm hypothesis: the French newborns could discriminate between English and Japanese, languages from different phonological classes, but not between English and Dutch, languages of the same class. In the third experiment, Nazzi and colleagues further examined the infants' attention to rhythm by testing if infants could discriminate between a shift from one rhythmic group to another (English + Dutch passages $\rightarrow$ Spanish and Italian passages) versus a shift from a non-rhythmic group to another non-rhythmic group (English + Italian passages $\rightarrow$ Dutch and Spanish passages). The newborn infants were only able to discriminate the first contrast where the language shifted from one rhythmic class to another. Thus, Nazzi and colleagues concluded that newborn are only able to discriminate languages from different phonological classes, and cannot discriminate 
language from within the same class. The use of low pass filtered stimuli in this experiment provided further support that at birth babies attend to the rhythmic properties of languages when performing discriminations. This conclusion is reasonable given that the fetus begins hearing sounds during the last trimester of pregnancy, and researchers believe that the womb acts as a low pass filter exposing the fetus to the rhythmic properties of language (Mehler et al., 1988). Taken together, these findings provide clear support for the Rhythm-based language discrimination hypothesis.

It is important to note that although the available newborn research supports the rhythm hypothesis, the data are still quite limited and, in particular, no study to date has examined an intraclass discrimination where one of the languages tested was native to the infant. Although researchers are aware that babies can hear languages in utero they do not know what affect this prenatal exposure has on language discrimination. Thus, it remains possible that, due to prenatal experience, intraclass discriminations are possible at birth when one of the languages being tested is familiar. Future research should examine this possibility. If newborns can discriminate their native language from a rhythmically-related language at birth, the rhythm-based language discrimination hypothesis would need to be re-evaluated.

\section{ii) 2-month-olds.}

Two studies examining language discrimination in two-month-old infants are reported in the literature. The first study is the pioneering research conducted by Mehler and colleagues (1988), discussed above. This study also included studies with 2-monthold English-learning infants who were tested using the same stimuli and contrasts that were used with the French newborns (English/Italian and French/Russian). A fixation procedure was used with the 2-month-old infants instead of the HAS procedure. In this 
procedure, infants looked at a projection screen where a picture of a woman was placed. Similar to the HAS procedure, during the initial stage one language was presented and after a specific habituation criterion was met the second language was presented. In this procedure, however, the infant's looking time towards the projection screen was measured and compared for each language as an indication of the infant's interest level. Mehler and colleagues (1988) found that the English 2-month-olds could discriminate English and Italian sentences, but not Russian and French sentences. These findings suggest that 2-month-old infants require familiarity with one of the languages to perform a discrimination. Unlike the newborn babies, the 2-month-olds still failed to discriminate the two languages when the data was reanalysed in 1994 (Mehler \& Christophe).

More recently, Christophe and Morton (1998) performed some language discrimination experiments with 2-month-old English infants. They utilised an adapted version of the contingent HAS procedure (see Hesketh, Christophe, \& DahaeneLambertz, 1997) where the infant needed to produce three high-amplitude sucks in order to trigger a stimulus and the number of sentences played per language was recorded rather than the number of sucks per language. The infants listened to passages that were produced by four female native speakers of each language in adult-directed speech. Consistent with the 2-month-old results from Mehler and colleagues (1988), these researchers found that the English infants could discriminate English from Japanese, but not French from Japanese. In order to determine how specific the 2-month-olds' representation of their native languages was, two more discriminations were performed: Dutch versus Japanese and Dutch versus English. In both experiments, the infant's increase in sucking was only marginally significant, suggesting that some babies 
discriminated the contrast while others didn't. Both of these results are rather difficult to explain in light of the previous literature.

The results of Christophe and Morton's (1998) study showing that some English 2-month-old infants could discriminate Dutch and Japanese while other could not is a rather complicated finding. The failure of some of the infants to discriminate this pair of rhythmically different foreign languages is consistent with other data from 2-month olds suggesting that 2-month olds require familiarity with one language to perform a discrimination. As for the infants that could perform this discrimination, the authors suggest that these infants may have been willing to accept Dutch as being their native language since it is rhythmically similar to English; however this conclusion is questionable considering that some of the infants could discriminate Dutch from English. In addition, for the infants that could not discriminate these two foreign, rhythmically different languages, this suggests a decline in language discrimination skills compared to newborns who succeeded when tested with such a contrast. To further complicate matters, studies with 5 month-olds (reviewed below) converge with newborn findings, also evidencing discrimination of unfamiliar rhythmically different languages. At present, there are two possible explanations. It is possible that these age differences are real and reveal the U-shaped learning curve occasionally seen in language development. In this case, the 2-month-old's inability to discriminate two rhythmically different foreign languages may represent an intermediate stage between the newborn's innate sensitivity to language rhythm and the learned abilities of a 5-month-old. A second alternative is that the discrepancy is due to the use of different test procedures across these age groups. Hence, the 2-month-olds may also discriminate two foreign rhythmically different 
languages if different measures are implemented. Clearly further research is needed to understand these age differences.

Another surprising result in the Christophe and Morton (1998) study was the English 2-month-old infants' ability to discriminate English and Dutch. This is in contrast to the newborn French infants in Nazzi's study (Nazzi et al., 1998) that could not discriminate this same contrast. This could be evidence that a developmental trend has occurred between birth and 2 months due to increased exposure to the native language. In addition, the marginally significant result might reflect that this ability is emerging at 2 months of age. Another explanation is that although the language contrast was the same for both studies, the task was not comparable. The English 2-month-olds were performing an intraclass discrimination from within their native rhythmic class in contrast to the newborn French infants who were not familiar with this rhythmic class. Once again, further research is needed to determine if newborns can perform an intraclass comparison from within their native rhythmic class in order to clarify this issue.

iii) 4 and 5-month-olds.

The first study to examine language discrimination in this age range provided evidence that 5-month-old infants can discriminate rhythmically different languages (Bahrick and Pickens, 1988). In this experiment, a female bilingual speaker of English and Spanish produced sentences in both languages using adult-directed speech. Infants were tested using a visual fixation procedure. In this procedure, infants were tested with audio-visual displays of the talker and also a visual-only condition to see if infants could discriminate languages using only the visual cues. Infants observed a monitor in front of them with a woman reciting different passages in the first language followed by passages in the second language during the test trial. Looking time was recorded to determine if 
the infants discriminated between the two languages. This study revealed that 5-monthold monolingual English infants could discriminate between English and Spanish utterances when audio-visual stimuli were used but not when only the visual speech information was presented.

About a decade later, Bosch \& Sebastián-Gallés published two studies that investigated monolingual language discrimination with 4-month-old Spanish and Catalan infants $(1997,2001)$. Their 1997 experiment utilised a novel procedure, where two loudspeakers were placed on either side of the infant and the stimuli were played alternating between the speakers. The infants' reaction time in looking towards the speaker when a stimulus was played was measured and compared across languages. Using this procedure with monolingual infants, they found that infant reaction times were faster to their native language and interpreted this as evidence that infants could respond differentially to a pair of languages. Their stimuli consisted of samples of infant-directed speech produced by a quadralingual speaker of Spanish, Catalan, English and Italian. Their 2001 experiment utilised a selection of the stimuli from their 1997 study, and a more conventional measure of language discrimination, a modified version of the familiarization-preference procedure described by Jusczyk and Aslin (1995). In this procedure, infants were placed in a booth facing three monitors displaying colourful animated images. This procedure involved a familiarization phase followed by a test phase. In the familiarization phase, samples from one language were presented on a loudspeaker hidden behind either the right or left monitor. The infant's looking time towards the monitor was recorded as an index of the infant's listening time. In the test phase, new samples of both languages were presented and looking times to each language were compared. In this paradigm, infants who discriminate the languages were expected 
to show a novelty response in the test phase (i.e. listen longer to new samples of a new language than to new samples of the familiarized language). The findings reported in these two studies revealed that monolingual Spanish and Catalan infants could discriminate their native language from English, and from the other non-native language, Spanish or Catalan. In addition, the infants were able to discriminate these languages when the stimuli were low pass filtered indicating that language rhythm provides enough information for discrimination. These studies are particularly interesting, as they provide the first clear evidence that infants are able to discriminate their native language from a foreign language of the same phonological class. According to the TIGRE model, the additional experience of older infants enables them to fine-tune their discriminations such that discriminations that once were not apparent become so with age (Mehler et al., 1996). Proponents of this model would claim that this study demonstrates that 4-montholds can perform an intraclass discrimination that newborns would be incapable of performing. However there are two important considerations to bear in mind. First, this study employed a single talker and infant-directed speech, hence the stimuli utilised in this research were less complex than those used in some previous studies. Thus it remains possible that an intraclass discrimination was evidenced in this experiment because the task was easier for the infants compared to previous studies. Second, as mentioned above, further research is needed to determine whether or not newborn babies are in fact capable of performing a native intraclass discrimination.

The studies reviewed thus far suggest that an evolution may occur between birth and 4 months permitting infants to perform intraclass discriminations. Thus, the rhythmbased language discrimination hypothesis can no longer account for these discriminations. Nazzi and colleagues (2000) consequently proposed three hypotheses 
that describe which linguistic properties an infant might attend to in order to perform intraclass discriminations once they are a few months old. The rhythmic-class acquisition hypothesis posits that, language discrimination skills evolve during infancy so that infants become more sensitive to the entire rhythmic class of their native language (Nazzi et al., 2000). According to this view, all intraclass disriminations within the native rhythmic class are possible, while intraclass discriminations from foreign rhythmic classes are not possible. In contrast, the native language acquisition hypothesis claims that infants learn the rhythmic properties specific to their native language rather than the whole rhythmic class (Nazzi et al., 2000). This pattern of acquisition would not be surprising considering that phonetic and phonotactic development occurs in this manner (Jusczyk, 1997). According to this hypothesis, the native language should be discriminated from a foreign language of the same rhythmic class, whereas two foreign languages from the native rhythmic class should not be discriminated (unless one is particularly similar to the native language), and two foreign languages from the same foreign rhythmic class would not be discriminated. A third viable hypothesis is the maturation hypothesis which asserts that infants should discriminate any two languages that sufficiently differ acoustically (Nazzi et al., 2000), and hence discrimination abilities are not shaped by experience with a specific language or language-type. If this view is correct, we would expect infants to discriminate intraclass languages both within the native and foreign rhythmic classes. To compare these hypotheses, Nazzi and colleagues (2000) designed a series of experiments involving different intraclass comparisons.

Nazzi and colleagues (2000) utilised the headturn preference procedure (HPP) to create a familiarization-preference test paradigm. This method involved a familiarization phase and a test phase similar to that utilised by Bosch and Sebastián-Gallés (2001), 
except that flashing lights were used in this experiment to maintain the infants' attention instead of visual monitors. The stimuli utilised in this study were taken from their previous study (Nazzi et al., 1998) and consisted of language samples produced by four female speakers of each language in adult-directed speech. In this series of experiments, Nazzi and colleagues (2000) first demonstrated that 5-month-old infants are able to perform interclass discriminations. The 5-month-old American-English babies discriminated samples of British-English and Japanese, and also samples of Italian and Japanese. In contrast, the English infants failed to discriminate a pair of rhythmically similar foreign languages, Italian and Spanish, which indicates that a simple maturation hypothesis cannot account for the infants' language discrimination abilities. AmericanEnglish infants also failed to discriminate two foreign languages drawn from their native rhythmic class, Dutch and German, which fails to support the rhythmic-class acquisition hypothesis. The American-English infants discriminated British-English and Dutch and also discriminated British-English and American-English. Taken together, these findings suggest that the native language acquisition hypothesis provides the best explanation for language discrimination among 5-month-olds. It appears that infants become increasingly sensitive to the rhythmic properties of their specific language rather than their entire rhythmic class. This permits infants to discriminate languages from within their native rhythmic class as long as one of the languages is the same or very similar to their native language. This also allows infants to discriminate two different dialects of their native language. Therefore, these experiments provide clear support for the native language acquisition hypothesis. 


\section{iv) Summary of Language Discrimination Studies.}

In summary, the above experiments can help us begin to develop a model of language discrimination development by illustrating that monolingual infants are capable of discriminating various language contrasts between birth and 5 months of age.

Newborn babies appear to discriminate specific language contrasts consistent with the rhythm hypothesis, which states that newborns attend to the rhythmic properties of languages and thus can only discriminate languages from different rhythmic classes. However, further research is needed to determine if newborns can perform a familiar intraclass language discrimination. The findings regarding 2-month-olds are unclear and changes related to age and language-experience require further investigation. At this point, it is not evident if 2-month olds can discriminate two foreign languages or if they can discriminate intraclass languages. By four months of age it is clear that infants can perform intraclass language discriminations. This may suggest that older infants are capable of more fine-grained discriminations than younger infants. It is, however, important to consider that the four-month-olds discriminated an intraclass language in a specific context: when one of the languages was familiar and the stimuli were produced by a single talker in infant-directed speech. Finally, support for the native language acquisition hypothesis indicates that 5-month-old infants perform interclass discriminations based on rhythm, and intraclass discriminations are possible if one of the languages is native or native-like; this skill is evident with adult-directed speech and multiple talkers. Thus, it appears that as infants gain more experience with their language their processing skills become more specific to their native language.

Although the above findings have begun to answer some of the basic questions regarding monolingual language development, there are still many questions that remain 
unanswered. Considering that at birth babies can discriminate two rhythmically different foreign languages, it seems that they do not even need to recognise their own language in order to complete some discrimination tasks. It appears that infants start out with some basic language discrimination skills but these skills are also shaped by age and language experience in the early months of life. Further research is needed to reveal the precise nature of the abilities infants bring to the task following prenatal exposure to speech and how these skills are refined in early development. At present, discrimination studies have not answered one of the most important questions: when do babies recognise their own language, and readily distinguish it from another language? It seems we need to rely on another methodological design to begin to answer this question.

\section{3) Monolingual Preference Studies}

Language preference studies examine if an infant prefers listening to one language over another. These experiments are particularly informative because evidence of a language preference shows that the infant is able to discriminate the languages, yet it also provides additional information. A language preference indicates that the infant selectively attends to one of the languages presented, and suggests that the infant recognizes their native language since it is more familiar to him/her. According to the model outlined by Hunter and Ames (1988) preference measures can also provide insights into the amount of processing an infant has completed on their native language. These researchers investigated preference for familiar and unfamiliar objects and designed a multifactor model to describe infant preferences. They observed that prior to any exposure to two objects (of equal information value) infants will display no preference for one object over the other. As exposure to one of the objects increases, a preference for the familiar object emerges. With further exposure to an object, there is a transition 
period where no preference is observed, and following this a novelty preference emerges. Their research findings led Hunter and Ames to describe a basic preference curve (see Figure 1). Hence, preference for a familiar versus a novel item is largely dependant upon the amount of processing the infant has completed on an item. That is, infants are intrinsically motivated to explore and process information on the familiar item; once this item is fully explored, the familiar item is no longer of significant interest rendering the novel item increasingly attractive.

Figure 1

The basic preference curve described by Hunter \& Ames (1988)

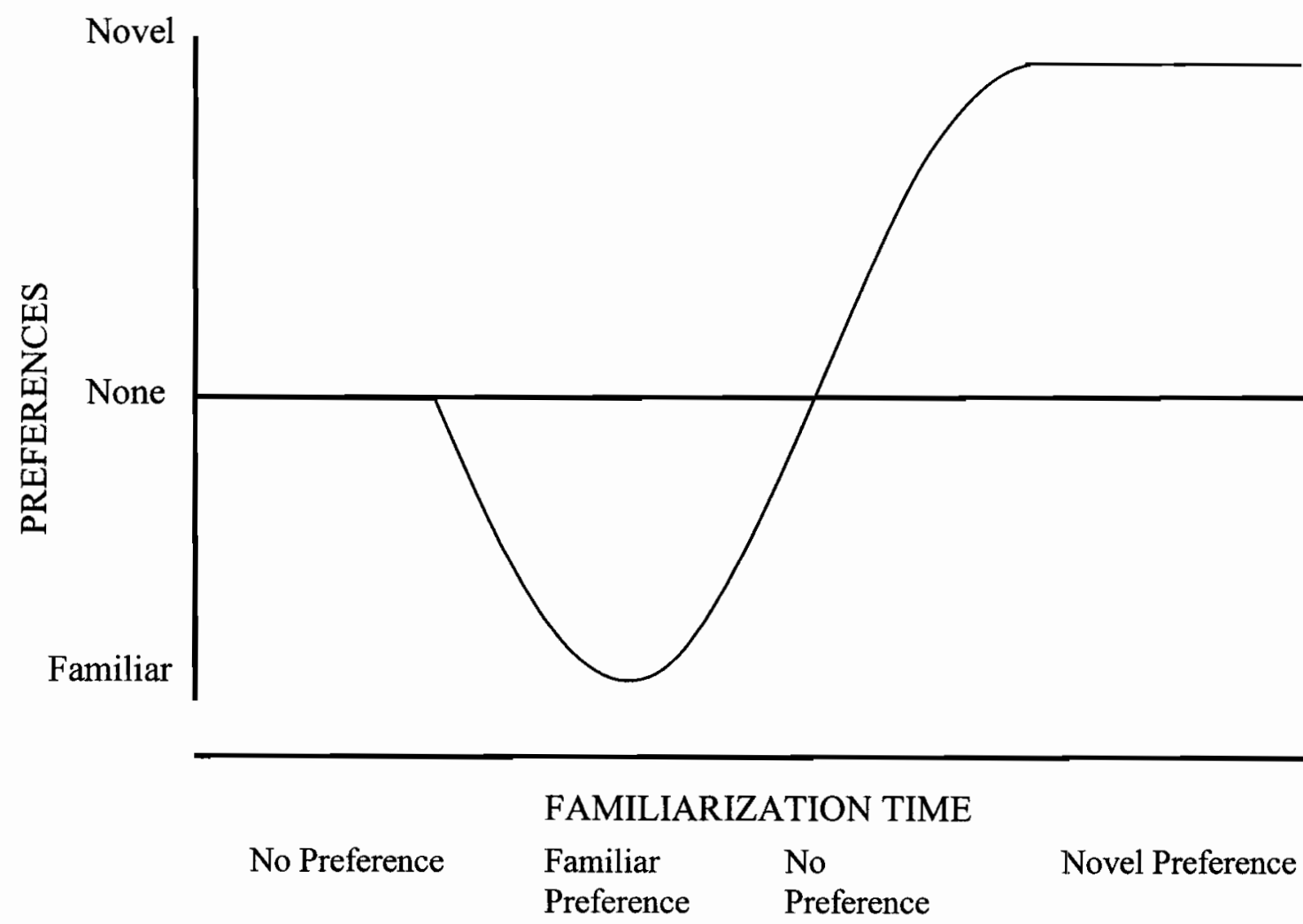


In the Hunter and Ames multifactor model three components significantly affect the basic preference curve: familiarization time, age, and task difficulty. According to the model, the same sequence of patterns always occurs as familiarization time increases, but the other two parameters, age and task difficulty, affect the rate of this sequence. With either increasing age or reduced task complexity, infants need less exposure time to shift from a familiarity to a novelty preference. Thus, older infants are expected to progress through this sequence faster than younger infants. Task difficulty can also affect the rate at which infants move through the sequence. When a task is more difficult, infants need more time to explore a stimulus or stimulus array and hence produce a slower pattern rate compared to easier tasks.

Although Hunt \& Ames examined preference in another domain, it is probable that the patterns they observed are not specific to this domain, but can be applied to infant preference in general. Therefore, if language preference investigations reveal a familiarity preference this would indicate that the infants are actively exploring properties of the familiar, or native, language; whereas, a novelty preference would imply that the infants have processed the native language to a level where the novel language is more appealing. It is important to note, that in this view, a lack of preference can be interpreted in two ways. No preference could mean that infants are still in the initial processing stage where native and non-native language samples are equally appealing to infants since they have not yet had enough experience with their native language to show a familiarity preference. However, no preference could also mean that infants are in a transition period between a familiarity preference and a novelty preference. Measuring preference at more than one age, or level of language exposure, can distinguish between these two possibilities. In the case of language preference, age and language experience are 
confounded since infants are exposed to language from birth. Consequently, if language preference is assessed at two different ages each result will indicate what stage in the sequence the infant has achieved due to the combined effects of age and increased exposure to their native language. Task difficulty could also considerably affect the rate of a language preference curve. When measuring language preference, variables such as the number of languages presented, the number of different talkers used, the use of adult versus infant-directed speech, the use of filtered or unfiltered speech, and the behavioural response being measured (e.g. eye movement versus headturns) can alter the difficulty of the task and thus affect the rate of the preference curve and the results obtained. It is thus essential to carefully consider these variables when analysing the results of language experiments. Clearly, language preference studies will improve our understanding of infant speech processing abilities.

There are three studies that have examined language preference in infancy and only two of these studies were designed specifically to investigate language preference (see Table 2 for a summary of monolingual preference studies). The pioneering experiments by Mehler and colleagues (1988) were not intended to examine language preference; however they provided the first indication that newborns may prefer listening to their native language. In their newborn experiments, the order of language presentation was always counterbalanced. When infants were tested on discrimination of French and Russian sentences, half of the infants were presented with French during the habituation phase followed by Russian in the test phase, and the other half heard Russian and then French. In these experiments, some interesting asymmetries were observed: (a) In the initial habituation phase, French newborns sucked longer when listening to French passages than to Russian passages, and (b) In the second phase an increase in sucking was 
only observed when the language shifted from Russian to French (that is, a shift to the preferred and native language), but not when the language shifted from French to Russian. These findings suggest that the French newborns preferred to listen to their native language. Consistent with this interpretation, no asymmetries were evident in the data gathered to test discrimination of Italian and English.

A decade later, Moon, Cooper and Fifer (1993) designed an experiment to directly examine language preference with newborn Spanish and English babies. Their stimuli included passages produced by eight English-speaking and eight Spanish-speaking women using adult-directed, unfiltered speech. Each child in this study listened to only one of the English and one of the Spanish speakers. A variant of the HAS procedure was used so that a sucking burst (a minimum of three consecutive sucks) resulted in stimulus presentation and vowel signals were presented in between sucking bursts. The duration of sucking bursts was recorded and compared across languages to indicate language preference. A native language preference emerged after the infants had listened to the stimuli for more than 12 minutes. The English babies preferred listening to English passages, while the Spanish babies preferred listening to Spanish passages. Clearly, the language an infant prefers is not an innately universal property, but rather an acquired, language specific characteristic that relies on the infant's prenatal language exposure. These experiments demonstrate that newborns prefer their native language and imply that newborns have some ability to recognise their language. In addition these experiments imply that newborns are likely processing and learning language-specific properties when they preferentially attend to their native language.

Hayashi, Tamekawa and Kiritani (2001) conducted the other systematic examination of language preference. They designed a study that assessed language 
preference with Japanese infants between 4 and 14 months of age. The stimuli consisted of 20 second samples of English and Japanese produced by a female bilingual speaker of both languages in infant-directed speech. The headturn preference procedure (see Kemler Nelson et al., 1995) was utilised where passages in each language were presented from loudspeakers on either side of the infant and listening time was compared across languages. In contrast to the newborn studies, the younger infants (4-6 months) did not show a significant preference for either language, whereas a developmental change occurred such that the older infants (7-14 months) preferred their native language. It seems rather unusual that this study did not evidence a native language preference at 4-6 months considering the results of the two previous studies. One possible explanation, consistent with Hunter and Ames (1988), is that the task difficulty was greater in this study given that different test procedures were used in the newborn studies and the Hayashi et al study. Another possibility is that stimulus duration is responsible for these results. Recall that Moon and colleagues (1993) did not detect a native preference until after 12 minutes of stimuli had played, thus the shorter stimulus duration of the experiment by Hayashi and colleagues may have prevented detection of a preference. Likewise, the stimulus durations were considerably longer (several minutes) in the newborn experiments conducted by Mehler and colleagues (1988) where a native language preference was observed. Another alternative is that infants demonstrate a native language preference at birth which diminishes around 4-6 months and returns at a later age. This U-shaped preference pattern would be consistent with other experiments reported by Hayashi and colleagues where a U-shaped preference curve emerged when they examined age effects on preference for infant-directed over adult-directed speech 
(Hayashi et al.). Clearly, there is very little data on language preference and the results to date are fairly unclear.

There are also unresolved questions as to how the preference patterns outlined by Hunter and Ames apply to preference for spoken language. Speech is a highly complex, multidimensional signal. When we present raw, unmodified samples of natural speech to infants, it is far from clear what feature(s) the infants are processing. In young infants, the features that are salient are likely to be limited by their processing capacities or bias. However, as infants grow their cognitive and linguistic capacities also expand making it possible for them to access multiple dimensions of the speech signal, and also making it more difficult for us to determine what aspects of the speech signal they are attending to. Thus, although preference studies using unmodified speech samples are a useful starting point for understanding the development of language preference, it is also important to determine what information in the signal results in a preference. This could be examined by using highly controlled speech materials, such as low-pass filtered speech. Research to date on language preferences is clearly quite limited, leaving many questions unanswered.

The above studies taken together provide an emerging picture of monolingual language development patterns that deserve further exploration. It appears that infants, and in particular newborns, may recognise and prefer their native language. In addition, language discrimination is initially based on rhythm and these linguistic properties become increasingly language specific with age. Unfortunately, this attempt to describe monolingual language acquisition can only provide a limited picture of what bilingual development looks like. These studies cannot determine if bilingual infants would follow the same pattern of development, or the same rate of development. We do not yet know 
if exposure to two languages would affect the types of discrimination an infant is capable of, and if discrimination of the two native languages would be dependent on similarity between the languages and the rhythmic class to which they belong. Moreover, we do not know if bilingual infants would prefer both of their languages equally, or if one language would be dominant. Unfortunately, only a scarce amount of research exists to answer these fairly basic questions.

\section{4) Bilingual Language Discrimination and Preference}

Over the past few decades, conflicting views have emerged regarding bilingual development. For instance, some people believe that bilingualism strains a child's linguistic system, leading to delayed or deviant language development. Some parents are concerned that babies are not capable of discriminating the two languages in their environment, and due to a fear of confusing the child they limit the child's environment to one language. Another concern often voiced is that the child will receive less exposure to both languages and thus is at a linguistic disadvantage. At the same time, bilingualism is often viewed as advantageous by providing the child the ability to communicate in two languages. It is also possible that exposure to multiple languages enhances cognitive development (Bialystok, 2001), and increased experience with languages permits the child to perform tasks that monolinguals are unable to perform. For example, it is possible that a bilingual French/Spanish newborn would be better able to discriminate a French/Spanish intraclass comparison than a monolingual child who has been exposed to only one of these languages. These conflicting viewpoints and theoretical concerns have resulted in research that compares monolingual and bilingual language development to determine if bilingual development is in fact deviant or delayed (for a review see Genesee, 2004). 
According to Fred Genesee, who conducted a review of this area, there is no evidence to support the claim that exposure to two languages compromises linguistic development (2004). Genesee claims that while small differences between monolinguals and bilinguals exist in terms of lexical and phonological domains, overall, and particularly in terms of morpho-syntax and socio-pragmatics, bilingual development parallels that of monolingual development at the verbal stage (Genesee, 2004). It still remains to be determined, however, if this is also the case with preverbal development. According to the unitary language system hypothesis, bilingual infants initially go through a stage where their languages are not differentiated (see Genesee, 1989, for a review). It would thus be interesting to examine if preverbal infants exposed to two languages possess one or two linguistic systems, and determine if this exposure results in a delay within the first year of life. Language discrimination and preference studies that determine if bilingual infants can discriminate their two languages, and that compare the results of monolingual and bilingual infants, would be one means of examining these questions.

Although bilingual discrimination and preference studies are clearly necessary, only three experiments have investigated these areas, and of these three experiments only two were specifically designed to assess bilingual infants (see Table 3 for a summary of bilingual studies). The first indication that bilingual infants can discriminate their two languages when they are rhythmically different from each other was revealed by Bahrick \& Pickens in their study of 5-month-old infants discussed above (1988). Recall that in this study the infants' looking time to adult-directed English and Spanish sentences was compared to determine if the infants could discriminate the two languages. In this experiment, a combined group of monolingual English and bilingual English/Spanish 
infants discriminated English and Spanish sentences. Although the experiments were not specifically designed to assess bilingual infants, additional analyses suggested that the bilingual infants could discriminate between their two languages.

Bosch and Sebastián-Gallés attempted to answer some of the questions regarding bilingual development by conducting the first study to directly test bilingual language discrimination and preference with 4-month-old infants. In their two studies discussed above, they included a group of bilingual Spanish/Catalan infants who were tested on the same language contrasts as the monolingual infants. Unfortunately, the use of their novel procedure in the 1997 study, that measured the infant's reaction time to the stimulus, made it rather difficult to interpret what precisely the experiments measured. In their article, Bosch and Sebastián-Gallés alternately used the terms language recognition, language discrimination, and language preference to refer to their results. Thus, it is not clear what precisely the differences in reaction time show, aside from a differential response to two different languages. Recall that when analysing the monolingual results, they observed that the infants reacted faster to their native language; according to Bosch and Sebastián-Gallés this faster orientation indicated that the infant's recognised and preferred this language, and were able to discriminate it from the other language. However, when the bilinguals were assessed using the same methodology, they oriented faster to the non-familiar language. According to their previous interpretation, this would suggest that the bilinguals recognised and preferred the non-familiar language and discriminated between the two languages presented. However, it seems rather unusual that the bilingual infants would recognise the non-familiar language. Thus, it is clear that reaction time differences in this procedure indicate that the two languages were 
discriminated, but any interpretation beyond that, regarding the infants' recognition or preference for a language, is questionable.

The results of Bosch \& Sebastián-Gallés's 1997 study revealed that the bilingual infants could "discriminate" Spanish or Catalan from English and from Italian. This is extremely important as it is the first clear evidence that bilingual infants can at least discriminate one of their languages from a phonologically similar or dissimilar language. However, when the Spanish and Catalan passages were compared, no significant differences in reaction times were observed. Due to the methodology, it is unclear whether this result reveals that the bilingual infants do not prefer one of their languages since both are familiar, or if it indicates that bilingual infants cannot discriminate between their two languages. To address this issue, Bosch and Sebastián-Gallés designed a second experiment using the same stimuli as in the first study but involving a more conventional procedure with listening time as the dependant variable (Bosch \& Sebastián-Gallés, 2001). This study established that bilingual Spanish/Catalan 4-month olds can in fact discriminate between their two languages. This is a remarkable finding since it is the first empirical evidence to verify that not only can bilingual babies discriminate between their languages, but they can do so even when the two languages are from the same phonological class. In addition this finding implies that infants exposed to two languages from birth may in fact possess two distinct linguistic systems. Finally, this study demonstrates that the bilingual babies are capable of performing the same tasks as their monolingual peers.

The research by Bosch and Sebastián-Gallés has helped advance bilingual development; however, it has still left many questions unanswered. For example, recall that in their 1997 study the bilingual babies displayed the opposite pattern of results 
compared to the monolingual babies. This is the first indication that the patterns of bilingual development may differ from that of monolingual development. However, in the second study the same pattern of results was observed for the monolingual and bilingual groups. Clearly, much more research with bilingual infants is necessary to resolve this issue. In addition, the stimuli used in the above studies included infantdirected speech from a single talker, thus future research needs to investigate if the same results can be observed when more varied and complex stimuli are utilised. Moreover, the methods utilised in the above studies did not allow us to determine when bilingual infants recognise their languages, and if they prefer one or both of their languages. Future research in this area must include a methodological design capable of testing these variables.

\section{5) The Present Research: A 3-Way Language Preference Paradigm}

The purpose of this thesis was to further explore early stages of bilingual language acquisition. Hopefully this research will help build more comprehensive models of language acquisition that encompass both monolingual and bilingual language development. Specifically this research aimed to investigate language preference with monolingual English, monolingual French, and bilingual English/French infants. As discussed above, previous bilingual studies have shown that bilingual infants can discriminate their two native languages from each other and from other non-native languages, but there is no evidence that bilinguals show a language preference indicating that their native language(s) are more familiar compared to a non-native language. When infants show a language preference, three inferences can be drawn: 1) that the languages can be discriminated, 2) that one language is favoured in attention and processing, and 3) that one language is more familiar to the infant than the other, which suggests a language 
recognition capacity (at least under the stimulus task conditions in which preference was measured). The current investigation was designed to measure language preference given that preference measures can provide insights beyond discrimination. The research by Bosch and Sebastián-Gallés contrasted the infant's two native languages; however, this method is not optimal for examining language preference with bilingual infants since it is possible that bilingual infants do not prefer one of their languages over the other since both languages are native. Thus, their method was not ideal considering that the null hypothesis is the expected result if bilingual infants prefer both of their native languages over an unfamiliar language. However, a three-way language contrast involving the two native languages and one non-native language would permit bilingual infants to demonstrate a preference for both of their languages over a non-native language, as well as a preference for one of their native languages over the other. To our knowledge, noone has conducted such a study to date. This research will thus be the first investigation of monolingual and bilingual language preference involving a three-way language contrast.

The participants in this study included monolingual English, monolingual French, and bilingual English/French infants, and the languages they heard were English, French, and Japanese. These languages were purposely chosen since they each represent a different rhythmic class. Rhythmically different languages were selected since there is strong support from previous experiments that infants can readily discriminate rhythmically different languages. The bilingual English/French environment in Montreal renders it an ideal location in which to conduct this experiment.

The goal of this study was to gain insights in to how infants respond to different languages in a natural language context where different talkers (i.e., different voices) are 
present and speech is not always produced in an infant-directed style. Bilingual studies conducted to date have involved single talkers and infant-directed speech. Thus, these studies cannot indicate if the infant is capable of discriminating languages in wider contexts. The stimuli used in this study were produced by multiple talkers using adultdirected speech samples that were not filtered. Although researchers have identified that infant-directed speech alters certain linguistic parameters in the speech signal that likely facilitate processing for infants, how these alterations differ across various languages is unknown. Thus, we chose to utilise adult-directed speech in this study since it will provide a more controlled comparison between the three languages.

As reviewed above, both monolingual and bilingual infants have been shown to discriminate interclass languages at all ages tested to date. It would thus be expected that the languages in the current study will be discriminated by the infants, a minimal requirement for a language preference to be observed. However, it should be noted that the use of three languages, multiple talkers, and unfiltered adult-directed speech will likely increase processing demands on the child. According to Hunter and Ames (1988), a difficult task will slow the rate of the preference pattern. Considering this, and the fact that previous language preference studies consistently reveal a familiarity preference, we expect infants in this study to demonstrate a native language preference (i.e. a familiarity preference).

\section{Experiment 1}

Since no study to date has involved a three-way language contrast, the task presented to the infants in this study will be more complex than any of the previous studies. It was thus decided that an appropriate first step would be to test monolingual infants first to determine if they are able to demonstrate a native language preference. 
Discrimination studies conducted by Nazzi and colleagues indicate that by 5 months of age monolingual infants possess some language specific processing abilities and are capable of performing very fine discriminations even when tested with multiple-talkers (Nazzi et al., 2000). We thus decided to begin our investigation with 6-month-old infants. Based on past research, and the complexity of this task, we predict that the infants will demonstrate a native language preference.

Method

Participants.

Infants raised in monolingual English and monolingual French environments were selected for this study. Infants were recruited from the island of Montreal (see Appendix A for a copy of the ethics certificate). All infants were healthy, full-term babies, with an uneventful medical history. To determine the child's language environment an experimenter interviewed the parents using a structured questionnaire that thoroughly examined the infants' language background (see Appendix B). In this questionnaire, parents were asked to describe their babies' language input and, when more than one language was present, they were asked to estimate the percentage breakdown of each language in their child's environment. In addition, parents were asked to list the caregivers and anyone that interacts with the child on a regular basis, and indicate the language(s) used by each of these individuals when interacting with baby, and to list the number of hours per week each individual would typically interact with the infant. From this information an estimate of the infant's language background was calculated (i.e. percentage of each language in the input) and compared to the parents estimate. In most cases, the parents estimate and our calculations were similar hence the parent's estimate 
was utilised as the measure of language background. In this study monolingual was defined as a minimum of $90 \%$ exposure to the language.

Twenty-three 6-month-old infants were tested, however four babies were excluded from the study due to the following reasons: fussing and crying (3) and an equipment failure (1). Thus the final sample included data from 19 babies: 11 English and 8 French. The English and French babies had a mean age (range) ${ }^{1}$ of 5:27 (5:3 - 6:23) and 5:25 (4:30-6:10), respectively. There were six English boys, five English girls, three French boys, and five French girls in this study. At the end of the experiment, parents were given an infant certificate as gratitude for their participation in this study.

\section{Stimuli.}

Stimuli were created in English (Canadian), French (Quebecois/Canadian), and Japanese. The text used to read the English and Japanese passages were borrowed from Nazzi, Jusczyk, and Johnson (2000). However the Japanese passages were adapted to utilise Japanese characters rather than the Roman characters utilised by Nazzi and colleagues. The Japanese speakers in our study reported greater ease with reading the Japanese characters and their speech was observed to be more fluent. The French passages were created in our lab and were designed to be analogous to the English and Japanese passages. There were eight different passages per language, and each passage contained five unrelated sentences and 15-21 syllables per sentence (see Appendix $\mathrm{C}$ for passages $^{2}$ ).

Six female native speakers of each language were recorded reading the eight passages in adult-directed speech. Each speaker practiced reading the passages several

\footnotetext{
${ }^{1}$ Age is expressed in months: days.

${ }^{2}$ The Japanese passages included in the Appendix are the original passages written in Roman characters.
} 
times before recording them in order to produce fluent and natural speech. Disfluent passages were rerecorded until a satisfactory recording was obtained. Multiple speakers of each language were recorded to ensure that infants prefer a specific language rather than a specific speaker. To minimize voice quality differences within and between languages, we recorded women between the ages of 20 and 30. Participants were recorded in a soundproof booth using an AKG C1000S microphone and a Tascam DA-30 digital audio recorder. The recordings were digitised at $22050 \mathrm{~Hz}$ and a 16-bit quantization. For each language, three of the six speakers were selected to be used in this experiment. For each of these speakers, two out of their eight passages were selected as stimuli. Two different passages were selected for each speaker, so that the same passage was never repeated. The speakers and passages were selected by two experimenters who listened to the passages and attempted to minimize differences in speaking rate, voice quality, and pitch. Efforts were also made to equate the intensity of the stimuli and the pause duration between sentences. The English, French, and Japanese stimuli had a mean intensity (dB) and range of 73 (68-75), 75 (73-78) and 76 (75-77), and a mean frequency (Hz) and range of 200 (195-215), 224 (219-230), and 218 (203-232), respectively. Each passage was cut-off at 15 seconds so that the stimuli would be equal in duration. The final stimulus set consisted of six stimuli per language which were produced by three different speakers each reciting two different passages.

\section{Procedure \& Apparatus.}

Language preference was measured using the sequential preferential looking procedure (Cohen, Atkinson, \& Chaput, 2000), a method commonly used in infant speech perception studies (for a review of methods used in infant speech perception research see Polka, Jusczyk, \& Rvachew, 1995; Werker et al., 1998). In this procedure, the infant is 
presented with a fixed stationary visual display and at the same time the infant hears a speech sample coming from a loudspeaker located adjacent to the visual pattern. From previous research using this protocol, we can infer that when the infant is fixating on the visual stimulus s/he is also listening to the sound (Horowitz, 1974). Thus, looking time indexes listening time to the stimulus. Therefore, the infant's mean looking time during each language is calculated in order to determine if a preference for one of the languages exists.

Using this procedure, infants were tested in a three-sided pegboard booth measuring $6 \times 7$ feet inside a sound proof room. Infants were held on the lap of their caregiver who was seated on a chair six feet from the front of the booth. Infants faced a Sony SDMX72B computer monitor placed at the front of the booth. A Canon Optura 20 digital camera and two Audio Trak BS190 loudspeakers were placed on a shelf directly below the computer monitor. A long black curtain attached to the top of the booth covered the inside of the booth on all four sides so that only the computer monitor was visible to the caregiver and infant.

The program Habit 2000 (Cohen, Atkinson, \& Chaput, 2000) was used to run the experiment on an Apple Macintosh G4 computer. The computer displayed a flashing red light to signal the beginning of the experiment and obtain the infant's attention. When the infant oriented towards the monitor the first trial began. A checkerboard appeared on the monitor as a visual reinforcer during the trials while the auditory stimuli were played. Each trial lasted exactly 15 seconds. An experimenter seated outside the test booth observed the infant on a Panasonic WVCK 1420A monitor that was attached to the video camera. The experimenter recorded if the infant was looking directly at or away from the computer monitor by observing the infant's eye movements and the reflection of the 
monitor on the infant's cornea. The attention getter, the flashing red light, was displayed between each trial to obtain the infant's attention before the next trial began. The procedure was partially infant-controlled in that the infant controlled when each trial began by orienting towards the attention getter; but, the trial duration was not infant controlled since it lasted 15 seconds irrespective of the infant's looking pattern. Prior to the test trials, a pre-test trial consisting of non-vocal music was played to familiarize the infant with the procedure. This was followed by the 12 test trials. After the test trials, a post-test trial consisting of non-vocal music was played to ensure that the infant was still attentive. The infant had to demonstrate their continued attention by increasing their looking time during the post-test trial compared to the last two test trials to ensure that the infants were still paying attention to the stimulus. The experimenter and the caregiver listened to masking music on Peltor HT7A headphones so that they were blind to which language was being played, and thus could not bias the child.

The stimuli were presented through a Behringer UB1622FX-PRO mixer connected to a Harmon Kardon amplifier which was connected to the loudspeakers. The loudness levels ranged between $65-68 \mathrm{dBA}$. The order of stimulus presentation was carefully controlled within each test session, and counterbalanced across infants tested in each language group. Each infant listened to 12 test stimuli consisting of four stimuli from each language. There were six different presentation orders and two different groups; the two groups were identical in order except that different passages from the same speakers were used. All orders contained four blocks of three stimuli, with one stimulus from each language per block. In each order, each language occurred first in one trial block with one language occurring first in two trial blocks. Across the six orders, each language occurred in each position within a block (first, second, or third) an equal 
number of times. Finally, there were no more than three trials separating two trials of the same language (see Appendix D for stimulus order). Each stimulus was assigned an arbitrary number so that the experimenter was blind to the language order when conducting the experiment. For order of language types to be fully balanced within and across infants, an equal number of infants should be tested in each of the 6 orders.

Results

Each infant listened to 12 test stimuli consisting of four trials of each language. For each child, a listening time was computed for each language by averaging the looking times to each language. For the English learning infants, the mean listening time (and SD) in seconds was 7.65 (1.42) for English, 7.29 (2.26) for French, and 7.18 (2.07) for Japanese (see Figure 2). For the French learning infants, the mean listening time (SD) was 8.55 (2.32) for English, 8.01 (1.59) for French, and 8.93 (2.63) for Japanese (see Figure 3). For each group of infants (English-learning and French-learning) a one way ANOVA was conducted with Language Stimuli (English, French, Japanese) as a within subject factor to assess whether infants showed a language preference. For the English infants, this ANOVA failed to show a significant effect of Language Stimuli on listening time scores, $\mathrm{F}(2,10)=.488, \mathrm{p}=.621$. Likewise, for the French-learning infants, the ANOVA was non-significant, $\mathrm{F}(2,7)=1.956, \mathrm{p}=.178$ 
Figure 2: English 6-month-old's listening times to English, French and Japanese stimuli

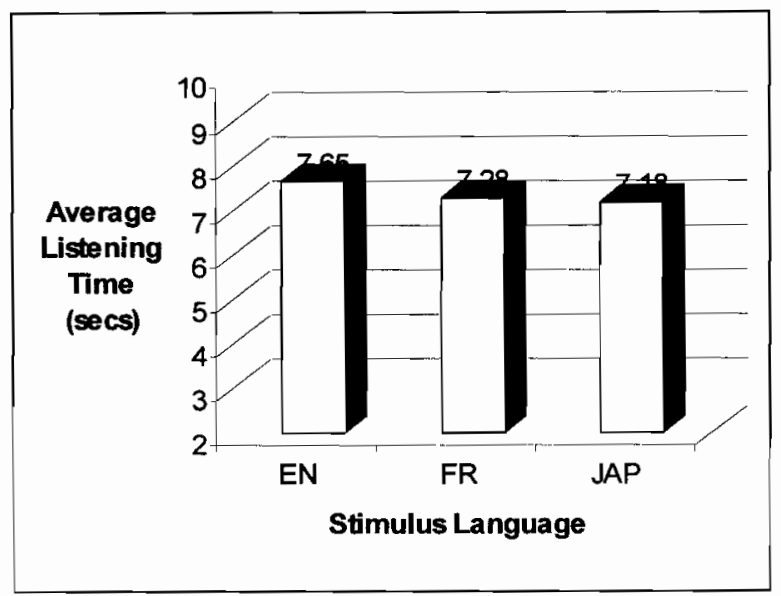

Figure 3: French 6-month-old's listening times to English, French and Japanese stimuli

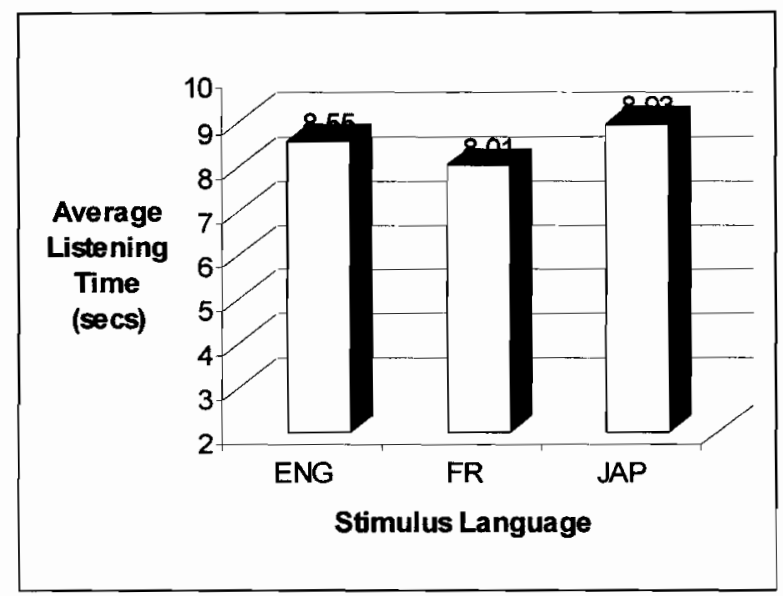

To determine if the infants preferred to listen specifically to their native language over either of the foreign languages, the listening times for the two foreign languages were combined and compared to the native language for each infant. For the English infants, the mean listening time (SD) in seconds to the native language (English) was 7.65 (1.42), and to the non-native languages (French + Japanese) was 7.23 (2.03). A paired ttest revealed no significant difference in listening times for the native and non-native stimuli, $\mathrm{t}(10)=.897, \mathrm{p}=.391$. For the French infants, the mean listening time (SD) in seconds to the native language (French) was 8.01 (1.59), and to the non-native languages 
(English +Japanese) was 8.74 (2.42). Once again, a paired t-test revealed no significant difference for the French infants, $t(7)=-1.575, p=.159$. These data indicate that monolingual 6-month-old infants failed to show a preference for their native language over a rhythmically different foreign language.

Recall that for order of language to be fully balanced within and across infants, an equal number of infants should have been tested in each of the 6 orders. Ideally, this experiment should have included an equal number of participants per language group, and the number of participants per group should have been a multiple of six considering that there were six different stimulus orderings. Unfortunately, difficulty obtaining infants that met the language requirements of this study limited the number of participants; however, there was at least one participant in each order. Thus, two additional analyses were conducted to determine whether a language preference would emerge if order was better controlled across and within participants. First, we re-anlayzed the data using the six subjects per language that comprised a balanced group within each language group. However, the results of these analyses were still not significant. Second, we repeated our analyses but with the listening times to the first block of trials removed from each infant's data. This was done because the effects of order on the listening time in a sequential preference test are typically due to the instability of listening times in the first trial or first trial block. Using these new listening scores (with the first block removed) the data were re-analyzed with both the initial group of infants (the larger, unbalanced sample size) and with the smaller groups of six infants (in which order was balanced across subjects). However none of these analyses revealed any significant differences in listening time across languages. 
Finally, to determine if all infants in this study would demonstrate a preference for one of the languages tested either due to some variability in the stimuli, or an inherently salient property in one of the languages, the results of the English and French infants were combined and re-analysed. For all babies, the mean listening time (SD) in seconds to the English passages was $8.03(1.85)$, the French passages was 7.59 (1.99), and to the Japanese passages was 7.92 (2.42). A one way ANOVA failed to show a significant effect of Language Stimuli on listening time scores, $F(2,18)=.835, p=.442$.

\section{Discussion}

This study demonstrated that monolingual English and French 6-month old infants did not display a preference when listening to passages in English, French, and Japanese. This result is surprising given Nazzi et al's (2000) evidence suggesting that 5-month-old infants can discriminate even dialectal differences within their native language. Moreover, this result is not consistent with the findings of Moon, Cooper, and Fifer (1993) who observed that at birth infants prefer listening to their native language when tested with unfiltered speech samples. However, the study by Moon and colleagues did not evidence this preference until 12 minutes of stimuli had played, whereas in the current study stimulus presentation was much shorter in duration. In contrast, the current study is consistent with the results of Hayashi, Tamekawa and Kiritani (2001) who found that infants did not demonstrate a language preference between 4-6 months of age. In their study, Hayashi and colleagues found that a native language preference emerged between 7 and 14 months of age. One possible explanation for the current findings is that it is more difficult for infants to show their sensitivity to their native language in a 3-way language preference test because the added stimulus variability increases the task difficulty. In this case, it is necessary to assess older infants with a three-way language 
contrast to determine if the added experience of older infants permits them to demonstrate a language preference. Experiment two was thus designed to examine this hypothesis.

\section{Experiment 2}

In this experiment, a three-way language contrast was used to examine language preference with 9-month old infants. Based on the work by Hayashi, Tamekawa and Kiritani (2001) it was expected that a native language preference would emerge. In order to learn more about bilingual language development, bilingual infants were included in this experiment so that their responses could be compared to the monolingual infants' responses. It was expected that the bilingual infants would also display a native language preference; that is they will prefer English and French over Japanese. The advantage of using a 3-way language contrast is that it will permit us to evidence a preference for both native languages over the unfamiliar language, or it can evidence a preference for one or none of the languages. If the monolingual and bilingual infants display a familiarity preference at the same age, this would suggest that the differences in language exposure patterns experienced by monolingual and bilingual babies does not alter how they begin to learn the properties of their native language. Differences in the language preference patterns between these two groups of infants would indicate that the input differences they experience influences how they learn about their ambient languages.

\section{Methods}

This experiment utilised the same methods as Experiment 1 except that 9-monthinfants participated in this study and three language groups were included. In addition to the monolingual English and French infants, a group of bilingual English/French infants was added. Bilingual was defined as a minimum of $30 \%$ and a maximum of $70 \%$ exposure to each language. 
Twenty-nine infants were tested but six were excluded for the following reasons: fussing and crying (2), maternal errors (2), the health of the child (1), and a failure to increase looking time during the post-test trial (1). The final sample included 23 infants: 7 English, 7 French, and 9 bilingual infants. The mean age and range in months and days for the English, French and bilingual babies was 9:5 (8;12 -9;27), 9;11 (8;16-10;9), and $9 ; 20(8 ; 12-11 ; 12)$, respectively. There were four English boys, three English girls, three French boys, four French girls, and nine bilingual girls in this study ${ }^{3}$.

Results

\section{Monolingual Infants.}

Each infant listened to 12 test stimuli consisting of four trials in each language. For each child, a listening time was computed for each language (English, French \& Japanese stimuli) by averaging looking times for each language. For the English-learning infants, the mean listening time (SD) in seconds was 8.25 (3.23) for English, 7.61 (2.69) for French, and 8.16 (2.93) for Japanese (see Figure 4). For the French learning infants, the mean listening time (SD) was 7.52 (1.97) for English, 7.38 (2.62) for French, and 7.85 (2.48) for Japanese (see Figure 5). For each group of infants (English-learning and French-learning) a one-way ANOVA was conducted with Language Stimuli (English, French, Japanese) as a within subject factor to assess whether infants showed a language preference. For the English infants, this ANOVA failed to show a significant effect of Language Stimuli on listening time scores, $F(2,6)=.745, p=.495$. Likewise, for the French-learning infants, the ANOVA was non-significant, $F(2,6)=.418, p=.667$.

\footnotetext{
${ }^{3}$ Although the bilingual sample consisted entirely of girls, there was no clear pattern with respect to sex among the bilingual babies that were excluded from the study. Hence this sex bias appears to be a bias in the subjects recruited into the study.
} 
Figure 4: English 9-month-old's listening times to English, French and Japanese stimuli

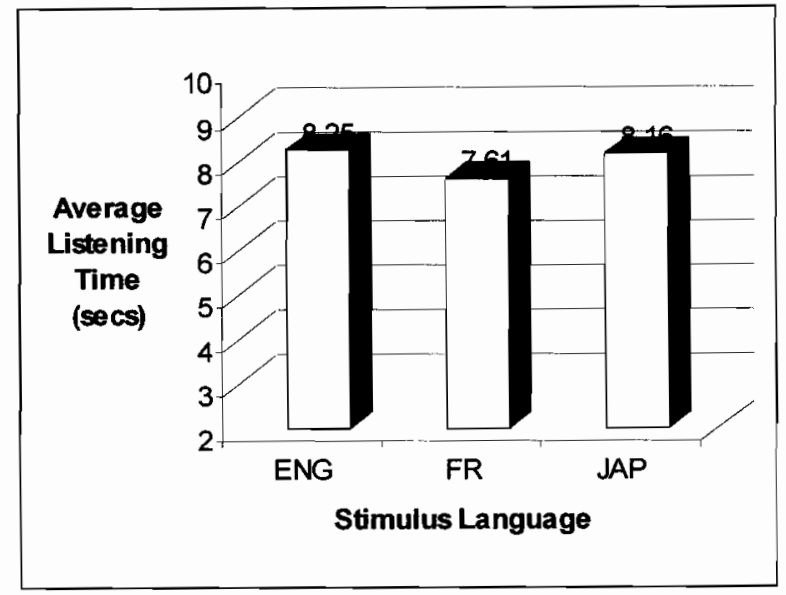

Figure 5: French 9-month-old's listening times to English, French and Japanese stimuli

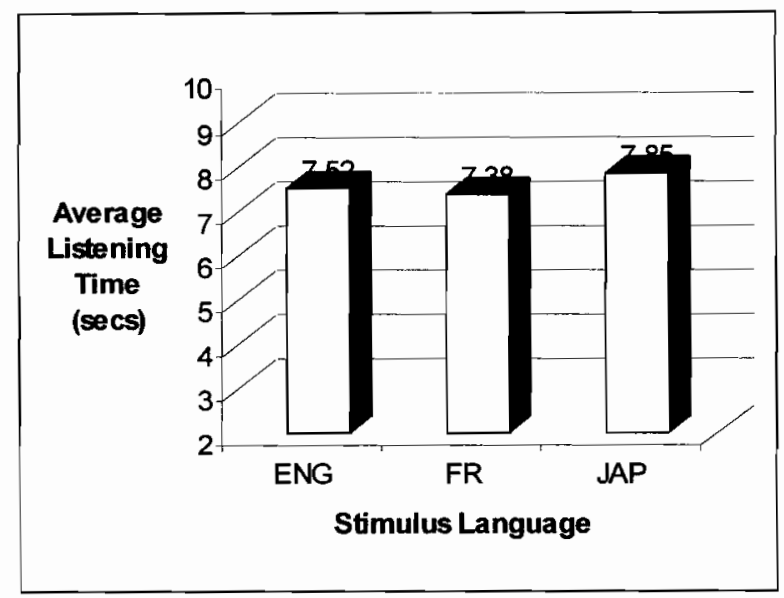

In order to determine if the infants preferred listening specifically to their native language over either of the foreign languages, the listening times for the two foreign languages were combined and compared to the native language for each infant. For the English infants, the mean listening time (SD) to the native language (English) was 8.25 (3.23), and to the non-native languages (French + Japanese) was 7.88 (2.71). A paired ttest revealed no significant difference in listening times for the native and non-native stimuli, $\mathrm{t}(6)=.750, \mathrm{p}=.482$. For the French infants, the mean listening time (SD) to the native language (French) was 7.38 (2.62), and to the non-native languages (English + 
Japanese) was 7.69 (2.14). Once again, a paired t-test revealed no significant difference for the French infants, $t(6)=-.613, p=.562$. These data indicate that these monolingual 9-month-old infants did not prefer their native language over a rhythmically different foreign language.

As in experiment 1 , additional analyses were conducted to better control for order effects. Analyses were repeated with presentation order balanced by reducing the sample size to six, and also after removing the first block of trials. However these analyses also failed to reveal a significant effect of Language Stimuli on listening times. In addition, the results of all the English and French 9-month-old infants were combined to determine if an overall preference pattern existed for all the babies. The mean listening time (SD) to the English passages was $7.89(2.60)$, the French passages was $7.49(2.55)$, and to the Japanese passages was 8.01 (2.62). A one way ANOVA failed to show a significant effect of Language Stimuli on listening time scores for the 9-month old infants combined, $F(2,13)=1.134, p=.331$. Finally, infants tested in Experiments 1 and 2 were merged according to language background to determine if increasing the sample size within each language group by merging 6 and 9-month olds would result in a significant effect. These data were analysed with the entire sample, with a reduced sample size containing balanced orders, with all blocks included, and with the first block removed; however no significant effect of language was observed for any of these analyses.

\section{Bilingual Infants.}

For the bilingual learning infants, the mean listening time (SD) in seconds was $7.46(1.89)$ for English, 7.03 (1.80) for French, and 6.30 (1.78) for Japanese (see Figure 6). A one way ANOVA with Language Stimuli as a within subject factor revealed a marginally significant result, $F(2,8)=3.39, p=.059$. Hence, the bilingual infants showed 
a strong trend towards a native language preference. To further investigate if the bilingual infants preferred their native languages over Japanese the results of the two native languages (English and French) were combined and compared to the Japanese data. A mean listening time of 7.25 (1.63) was observed for the native languages, compared to the mean of $6.30(1.78)$ for the Japanese stimuli. A paired t-test revealed a highly significant difference between the native languages and Japanese, $\mathrm{t}(8)=4.058, \mathrm{p}=$ .004. Examination of individual listening patterns revealed that each bilingual infant preferred listening to at least one of their native languages over Japanese: six out of nine of the infants listened longer to both the English and French stimuli compared to the Japanese stimuli, two infants preferred English over Japanese, and one infant preferred French over Japanese. Taken together, these results indicate that these bilingual English/French 9-month-old infants preferred listening to one or both of their native languages over Japanese.

Figure 6: Bilingual 9-month-old's listening times to English, French and Japanese stimuli

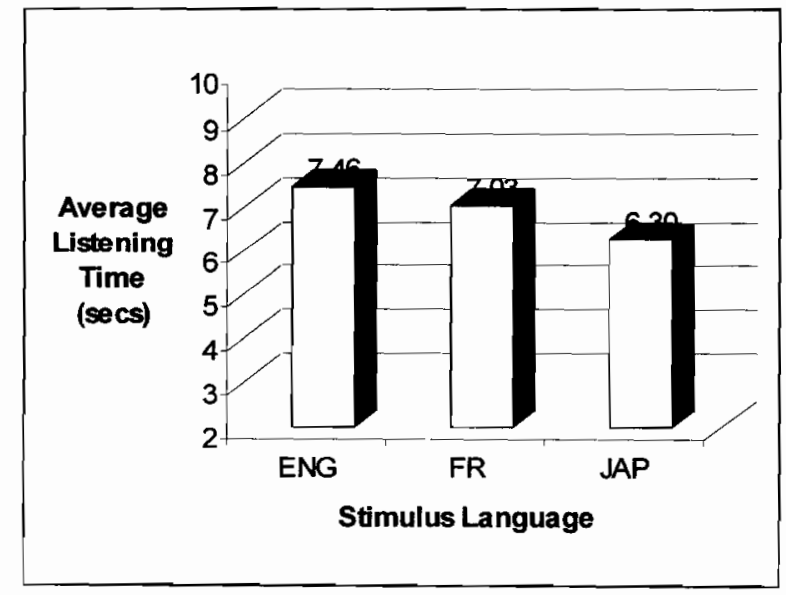

For each child, the listening scores were computed with the first trial block removed to minimize order effects. The mean listening time (SD) was 7.01 (1.76) for English, 6.36 (1.44) for French, and 5.71 (1.74) for Japanese. A one way ANOVA 
conducted with these scores showed the same pattern of results, that is a marginally significant effect of Language Stimuli $F(2,8)=.3 .18, p=.069$. The bilingual data were not analysed with a reduced sample size because a balanced sample where at least one infant was exposed to each stimulus ordering did not exist. Infants will continue to be recruited for this study, and future analyses will need to ensure that a balanced group of infants is examined. In addition, since all infants in this group were girls, future testing of bilingual infants will need to be limited to boys to ensure that a gender effect is not present.

\section{Overall Discussion}

Monolingual English and French 5 and 9-month-old infants did not demonstrate a language preference in this study. In contrast, the bilingual English/French 9-month-olds did display a preference for their native languages (English and French) over the nonnative language (Japanese). I will begin by discussing the monolingual results and then continue with the bilingual results.

Considering past research in this field, the monolingual results in this study are rather surprising. For instance, the results are inconsistent with research by Mehler and colleagues (1988) and Moon and colleagues (1993) which suggest that newborn babies prefer listening to their native language. While the 5-month-old infants' lack of preference in this study is consistent with the work by Hayashi and colleagues (2001), the 9-month-olds continued absence of a preference is not consistent with their work. Although there is very little previous literature on language preference, the results of the current study are nonetheless surprising considering that all of the previous studies have evidenced a native language preference at some age. Based on the variability observed in 
the past studies and the current study it seems that a clear language preference pattern is not easily identifiable and more research is needed in this area.

It seems reasonable to rule-out the possibility that the infant's inability to demonstrate a language preference in this study was due to the test procedure. First of all, the sequential preferential looking procedure has been used successfully in previous infant studies as a measure of preference for speech stimuli (Pegg, Werker, \& McLeod, 1992; Shi \& Werker, 2001; Werker et al., 1998). In addition, even with a small sample size, a clear, consistent native language preference was evidenced by the bilingual infants, thus confirming that this methodology is effective for measuring language preference. Moreover, the monolingual infants in this study demonstrated that they maintained their interest during the experiment by increasing their listening time during the post-test trial.

A language preference paradigm requires that the infant is able to discriminate the languages tested in order to demonstrate a language preference. Thus it is possible that the monolingual infants' lack of preference is indicative of an inability to discriminate the three languages. Considering past research, and the fact that we contrasted rhythmically different languages, this explanation seems unlikely. However. it is important to keep in mind that the literature to date is not extensive, and the use of three languages may have enhanced the difficulty involved in performing a discrimination. Yet it still seems probable that the infants should discriminate the languages in this study and the results likely reflect the monolingual infants' failure to selectively attend to their native language in a 3-way language preference task.

According to the Hunter and Ames (1988) model of preference, infants do not initially display a preference, then a familiarity preference develops, followed by a lack of 
preference, and finally a novelty preference emerges. If we apply this model to the results of this study, it is evident that the monolingual infants' lack of preference can signify two very different stages. The first possibility is that the infant's have not yet had enough experience with the native language to develop a preference for their language. The second possibility is that the infant's possessed a preference for their native language at some prior point and have had enough exposure to this language to move beyond this stage, but have not yet processed their language so thoroughly to transition into a novelty stage. One way to test which of these hypotheses is correct would be to perform the experiment with older infants since the first alternative would result in a familiarity preference with older infants, and the second alternative would result in a novelty preference. Considering that past research has evidenced a native language preference from birth until 14 months of age, and considering the complexity of the stimuli in this study, it seems most probable that the first alternative is correct.

As discussed by Hunter and Ames, it is essential to consider the effect of task difficulty on the preference pattern. Compared to previous studies, the stimuli in this study were significantly more difficult and, thus, may have delayed the preference pattern. In an attempt to test infants with more naturalistic stimuli, we utilised adultdirected, unfiltered speech with multiple talkers. In contrast, all of the past language preference studies have utilised a single talker, and all of the past bilingual studies have involved infant-directed speech and a single talker. Although some of the language discrimination studies have involved similar stimuli to this study, the design of a discrimination task is simpler than a preference task. Therefore, the task and stimuli in this experiment differ from previous experiments. Perhaps the most important difference between the current study and previous research was the use of three languages instead of 
two. It is possible that having three languages (and multiple talkers) made it very difficult for infants to recognize and allocate their attention to their native language. It is also possible that the number and duration of stimulus trials in the current experiment was not long enough for infants to demonstrate a native language preference. Recall that Moon and colleagues (1993) only observed a native preference in newborns after 12 minutes of stimuli had played. In summary, it seems probable that the monolingual infants in this study are in the first stage of the Hunter and Ames model and that these infants were not able to selectively allocate attention to their native language with the short and variable speech samples presented in the present task.

In future studies the use of simpler stimuli may yield the expected native language preference with monolingual infants. For instance, the use of a single talker or the use of two languages might result in a language preference. It may also be possible to observe a native language preference by manipulating the stimuli such that the amount of information available in the speech stimuli is limited. One way to test this would be to low pass filter the speech stimuli. Overall, given that there are many uncertainties as to how to apply the Hunter and Ames (1988) model to language preference, only further research will explain why we failed to observe a native language preference in monolingual infants.

In contrast to the monolingual infants, the bilingual 9-month-old infants in this study demonstrated a native language preference. Although the results are marginally significant at this point, only nine infants were included in this group. Since most of the infants in this group are displaying the same pattern, the addition of a few more infants (who conform to the present sample) will yield a significant result. The finding that bilingual infants prefer their native languages has added to the limited amount of research 
on bilingual infants and will help develop accurate models of bilingual language acquisition. This is a remarkable finding since it is the first evidence that bilingual infants prefer listening to their native languages over a foreign one. As outlined above, this significant language preference shows that bilingual infants can discriminate their native languages from a non-native language, they selectively attend to their native languages over a non-native language, and they recognize their native languages as being more familiar to them compared to a non-native language. Although past research has demonstrated that the language an infant is exposed to influences the way s/he perceives speech (Werker \& Tees, 1984; Moon, Copper \& Fifer, 1998; Nazzi et al., 2000; Hayashi et al., 2001), this study is particularly interesting since it provides evidence of languagespecific effects with bilingual infants. Moreover, this finding is the first indication that bilingual infants may recognise their native languages at 9 months of age. Finally, the results of this study imply that 9-month-old bilingual infants can perform an interclass language discrimination which is consistent with the findings of Bosch and SebastiánGallés (2001).

The bilingual results in this study are particularly interesting considering that the monolingual infants did not display a language preference given the same stimuli and the same experimental conditions. This finding is rather surprising since past research involving bilinguals has consistently demonstrated that bilingual language development is parallel to monolingual development or is initially slightly delayed and later converges with monolingual development. However, there has been no research to date demonstrating that bilingual infants are precocious compared to their monolingual peers. Returning to the Hunter and Ames model (1988), it seems that the bilingual infants could actually be behind or ahead of the monolinguals depending on what the lack of preference 
with the monolingual infants represents. If the monolingual infants' lack of preference represents a post-familiarity preference stage, which is the third stage of the model, then the bilingual infants' preference, the second stage of the model, would indicate that the bilinguals are behind their monolingual peers. If this is the case, the bilingual infants may still be processing the specific properties of their languages since they have two languages to process, while the monolingual infants who only have one language to process may have already had enough exposure to their native language. One way to test this hypothesis would be to conduct the experiment with older infants since older monolingual infants should display a novelty preference while older bilinguals should transition into a no preference stage. However, it does seem rather unlikely that the monolingual infants are at a later stage than the bilingual infants. As discussed above, past research and the level of task difficulty in this experiment would not suggest that the monolingual infants have obtained a post-preference stage. Moreover, if the monolingual infants had experienced a preference stage we must question when this stage occurred? Since we examined both 6 and 9-month-old infants in this study, we must have either narrowly missed a preference stage at seven or eight months of age, or the stage must have occurred prior to 6 months of age. While this is possible, it seems more likely that the monolingual infants are at the initial no preference stage and hence are behind the bilingual infants in this study.

Assuming that the bilingual infants are demonstrating a native language preference earlier than the monolingual infants, there are two possible explanations for this finding. The first explanation relies on the fact that the experiment was not precisely equivalent for the monolingual and bilingual infants. The bilingual infants were listening to three different languages where two of the languages were familiar and one language 
was unfamiliar. In contrast, the monolingual infants were listening to two unfamiliar languages and one familiar language. Thus, the task may have been easier for the bilingual infants who had greater experience and knowledge of the languages used in the experiment. It could thus be argued that this is not a fair comparison, and the monolingual and bilingual infants might in fact react similarly if the task was better equated. However, another explanation for why the bilingual infants are ahead of the monolingual infants is that perhaps the bilingual infants process language differently from the monolinguals. It is possible that being exposed to two rhythmically different languages causes bilingual infants to attend to language variability differently. If this is the case, then even when the experiments are better equated the bilinguals may continue to display a different pattern, and they may continue to display a different attentional response to language differences compared to monolingual infants. Such a finding could suggest that bilingual infants develop better skills for sorting multiple languages since they are accustomed to a multilingual environment in comparison to monolinguals who have less experience with such situations. Support for this alternative would be consistent with Bosch and Sebastián-Gallés's (1997) finding that the bilingual infants in their study demonstrated a different pattern of results compared to the monolinguals. Clearly, further research is necessary to establish which alternative is correct.

Although the task was not equivalent for the infants in this study, the present findings still indicate that the monolingual and bilingual infants differ in how they attend to speech variability. It is clear that there are many experiments that could follow from the current study to address the question of how and why these infants differ. In my opinion, the next step would be to modify the experiment such that it is comparable for both the monolingual and bilingual groups. One way to do this would be to utilise three 
languages such that one is familiar and two are unfamiliar to both the monolingual and bilingual infants. For example, monolingual English and bilingual English/French infants could listen to passages in English, Polish and Japanese. This task would be more comparable between the two groups and could help clarify the results of the current study. However, one of the concerns with the current experiment was that the use of three languages was too taxing for the infants. Since so many questions remain unanswered it might be best to first complete a study with a two-way language comparison where one language is familiar and the other is unfamiliar to the infants. For example, monolingual English infants would listen to English and Japanese passages, while monolingual French infants would listen to French and Japanese, and bilingual English/French infants would listen to either English or French and Japanese. Based on previous studies a native language preference would be expected for both the monolingual and bilingual infants. If the monolingual infants do not display a preference when only two languages are involved, it would further confirm that monolingual and bilingual infants attend to language variability quite differently. In this case, a careful comparison of language discrimination skills in bilingual and monolingual infants would be a useful follow-up. If the monolingual and bilingual infants demonstrate the expected native language preference in a two way preference test, we would then proceed with the 3-way language comparison described above.

After the follow-up studies described above have been conducted there are many additional experiments that could be completed to further investigate this question. For instance, it would be extremely useful to examine if 6-month-old bilingual infants demonstrate a language preference since this could be compared to the 6-month-old monolingual data. Also, this study did not specifically examine if the bilingual infants 
could discriminate between the English and French passages and based on the results it remains possible that the infants didn't discriminate these two languages. In addition, this study did not specify what information in the speech samples supported the preference pattern observed in the bilingual infants. Past research shows that the bilingual infants should be capable of discriminating the languages and that rhythmic properties are the underlying mechanism. However, it could be the goal of future research to specifically investigate this. A discrimination task comparing English and French could be used to specifically test if the bilinguals can discriminate their two native languages, and the use of low-pass filtered speech would help examine the means by which this discrimination is possible. It would also be interesting in the future to conduct this experiment with intraclass bilingual infants (e.g., French/Italian bilinguals) listening to passages in English, French and Italian passages to determine how fine-grained the infants preference is. As discussed above, low pass filtering could be used in future studies to examine if a novelty preference would emerge with older infants according to the Hunter and Ames model. There are clearly many different studies that could add to the current study. In conclusion, the results of this study have demonstrated that the sequential preferential looking procedure is an effective measure of language preference. It was observed that monolingual English and French infants do not demonstrate a language preference at 6 or 9 months of age in a 3-way language preference test. This result is rather surprising considering past research in this field. More research is needed to further investigate this issue and also to determine if the Hunter and Ames model (1988) applies to language preference. This study also provided the first indication that bilingual 9-month-old infants prefer and recognise their native languages, an unexpected result considering the monolingual findings. Further research involving two and three way 
language comparisons that are better equated for both the monolingual and bilingual groups are needed to determine if bilingual infants are in fact linguistically precocious. Bilingual language acquisition research is urgently needed to begin developing accurate, comprehensive models of language development. The current investigation attempted to initiate such research by comparing language preference with monolingual and bilingual infants. This research is one of the first indications that bilingual infants attend to language variation differently than monolingual infants. It is important to note that the attention pattern observed in bilingual infants reveals a processing bias that can be expected to facilitate their acquisition of two languages. Further research is needed to establish whether the language preference evident in bilingual infants reveals an early perceptual adaptation that supports bilingual acquisition. This research can provide valuable information to parents, educators, and professionals regarding bilingual development. For instance, there has been a long standing controversy debating whether bilingualism has positive or negative effects on development. Parents are often concerned that raising their child with two languages will delay their child's development. At this time, the current study appears to indicate the contrary - that bilingualism may in fact be advantageous to infants. Clearly, this research is only the beginning and much more research in needed to further investigate this issue. 


\section{References}

Bahrick, L. E. \& Pickens, J. N. (1988). Classification of bimodal English and Spanish language passages by infants. Infant Behavior and Development, 11, 277-296.

Bialystok, E. (2001). Bilingualism in development: Language, literacy, \& cognition. New York: Cambridge University Press.

Bosch, L. \& Sebastián-Gallés, N. (1997). Native-language recognition in 4-month-old infants from monolingual and bilingual environments. Cognition, 65, 33-69.

Bosch, L. \& Sebastian-Galles, N. (2001). Evidence of early language discrimination abilities in infants from bilingual environments. Infancy, 2 , 29-49.

Christophe, A. \& Morton, J. (1998). Is Dutch native English? Linguistic analysis by 2month-olds. Developmental Science, 1, 215-219.

Cohen, L. B., Atkinson, D. J., \& Chaput, H. H. (2000). Habit 2000: A new program for testing infant perception and cognition. (Version 2.2.5c) [Computer software]. Austin: University of Texas.

Cutler, A., Mehler, J., Norris, D. \& Segui, J. (1986). The syllable's differing role in the segmentation of French and English. Journal of Memory and Language, 25, 385400.

Cutler, A., Mehler, J., Norris, D. \& Segui, J. (1992). The monolingual nature of speech segmentation by bilinguals. Cognitive Psychology, 24, 381-410.

Cutler, A., \& Otake, T. (1994). Mora or Phoneme? Further evidence for languagespecific listening. Journal of Memory and Language, 33, 824-844. 
Genesee, F. (2004). Bilingual first language acquisition in perspective. Unpublished manuscript, McGill University, Montreal, Canada.

Genesee, F. (1989). Early bilingual development: One language or two? Journal of child language, 16, 161-179.

Harris, R. J., \& Nelson, E. M. M. (1992). Bilingualism: Not the exception anymore. In R. J. Harris (Ed.), Cognitive processing in bilinguals (pp. 3-14). Amsterdam: North Holland.

Hayashi, A., Tamekawa, Y. \& Kiritani, S. (2001). Developmental change in auditory preferences for speech stimuli in Japanese infants. Journal of speech, language, and hearing research, 44, 1189-1200.

Horowitz, F. D. (Ed.) (1974). Visual attention, auditory stimulation, and language discrimination in young infants. Monographs of the society for research in child development, 39, 1-140.

Hunter, M. A. \& Ames, E. W. (1988). A multifactor model of infant preferences for novel and familiar stimuli. In C. Rovee-Collier \& L.P. Lipsitt (Eds.), Advances in infancy research (pp.69-95). Norwood, NJ: Ablex.

Jusczyk, P. W. (1997). The discovery of spoken language. Cambridge, MA: MIT Press/Bradford Books.

Jusczyk, P. W. \& Aslin, R. N. (1995). Infants' detection of sound patterns of words in fluent speech. Cognitive Psychology, 29, 1-23.

Kemler Nelson, D. G., Jusczyk, P. W., Mandel, D. R., Myers, J., Turk, A., \& Gerken, L. A. (1995). The headturn preference procedure for testing auditory perception. Infant behaviour and development, 18, 111-116. 
Mehler, J. \& Christophe, A. (1994). Maturation and learning of language in the first year of life. In M. Gazzaniga (Ed.), The Cognitive Neurosciences: a handbook for the field (pp. 943-954). Cambridge, NJ: MIT Press.

Mehler,J., Dupoux, E., Nazzi, T., \& Dehaene-Lambertz, G. (1996). Coping with linguistic diversity: the infant's viewpoint. In J. Morgan \& K. Demuth (Eds.) Signal to syntax: Bootstrapping from speech to grammar in early acquisition (pp.101-116). Mahwah, NJ: Lawrence Erlbaum.

Mehler, J., Jusczyk, P., Lambertz, G., Halsted, N., Bertoncini, J., \& Amiel-Tison, C. (1988). A precursor of language acquisition in young infants. Cognition, 29, 143178.

Moon, C., Cooper, R. P., \& Fifer, W. P. (1993). Two-day-olds prefer their native language. Infant Behavior and Development, 16, 495-500.

Nazzi, T., Bertoncini, J., \& Mehler, J. (1998). Language discrimination by newborns: Toward an understanding of the role of rhythm. Journal of Experimental Psychology: Human Perception and Performance, 24, 756-766.

Nazzi, T., Jusczyk, P. W. \& Johnson, E. K. (2000). Language discrimination by Englishlearning 5-month olds: Effects of rhythm and familiarity. Journal of Memory and Language, 43, 1-19.

Otake, T., Hatano, G., Cutler, A., \& Mehler, J. (1993). Mora or syllable? Speech segmentation in Japanese. Journal of Memory and Language, 32, 258-278.

Pallier, C., Sebastian, N., Felguera, T., Christophe, A., \& Mehler, J. (1993). Attentional allocation within the syllabic structure of spoken words. Journal of Memory and Language, 32, 373-389. 
Pegg, J. E., Werker, J. P. \& McLeod, P. J. (1992). Preference for infant-directed over adult-directed speech: evidence from 7-week-old infants. Infant behaviour and development, 15, 325-345.

Polka, L., Jusczyk, P. W., \& Rvachew, S. (1995). Methods for studying speech perception in infants and children. In W. Strange (Ed.), Speech perception and linguistic experience: issues in cross-language research (pp. 49-89). Baltimore: York Press.

Ramus, F., Dupoux, E., \& Mehler, J. (2003). The psychological reality of rhythm classes: Perceptual studies. Paper presented at 15th International Congress of Phonetic Sciences, Barcelona.

Sebastian, N., Dupoux, E., Seguf, J., \& Mehler, J. (1992). Contrasting syllabic effects in Catalan and Spanish. Journal of Memory and Language, 31, 18-32.

Shi, R. \& Werker, J. F. (2001). Six-month-old infants' preference for lexical over grammatical words. Psychological Science, 12, 70-75.

Werker, J. F., Shi, R., Desjardin, R., Pegg, J. E., Polka, L., \& Patterson, M (1998). Three methods for testing infant speech perception. In A. M. Slater (Ed.), Perceptual development: visual, auditory, and speech perception in infancy (pp. 389-420). London: UCL Press.

Werker, J. F. \& Tees, R. C. (1984). Cross-language speech perceptions: Evidence for perceptual reorganisation during the first year of life. Infant Behaviour and Development, 7, 49-63. 
Appendix A

Ethics Certificate

\section{CERTIFICATION Of ETHICAL ACCEPTABILITY FOR RESEARCH INYOLVING HUMAN SUBJECTS}

The Faculty of Medicine Institutional Review Board consisting of:

$\begin{array}{ll}\text { SERGE GAUTHIER, MD } & \text { MARK S. GoldBERG, PHD } \\ \text { VinCENT GRACCO, PHD } & \text { MARIGOLD HYDE, BSC } \\ \text { ABBY LIPPMAN, PHD } & \text { PETR KAVAN, MD } \\ \text { HARVEY SigMAN, MD } & \text { SALLY TINGLEY, BCOM }\end{array}$

has examined the research project A05-B18-04B entitled "Beginning in Language Acquisition : The Infants' Perceptual Adaptation to Linguistic Diversity" as proposed by: $\quad \frac{\text { Linda Polka }}{\text { Applicant }}$ to Granting Agency, if any and consider the experimental procedures to be acceptable on ethical grounds for research involving human subjects.

June 9, 2004

Date
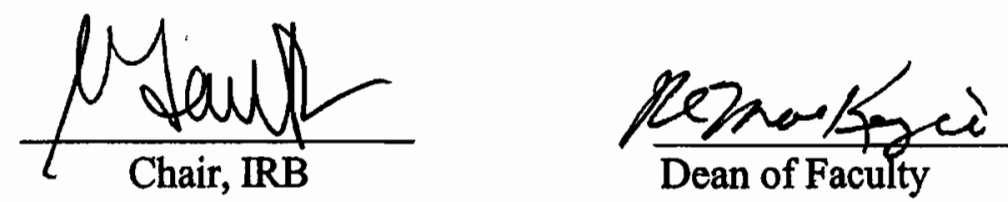


\section{Appendix B}

\section{Language Background Questionnaire}

Date :

Subject No :

Name :
Date of Birth : (full term?)

Home Phone :

\section{LANGUAGES SPOKEN BY FAMILY}

\section{To Each Other:}

Father's Parents

To Babv:

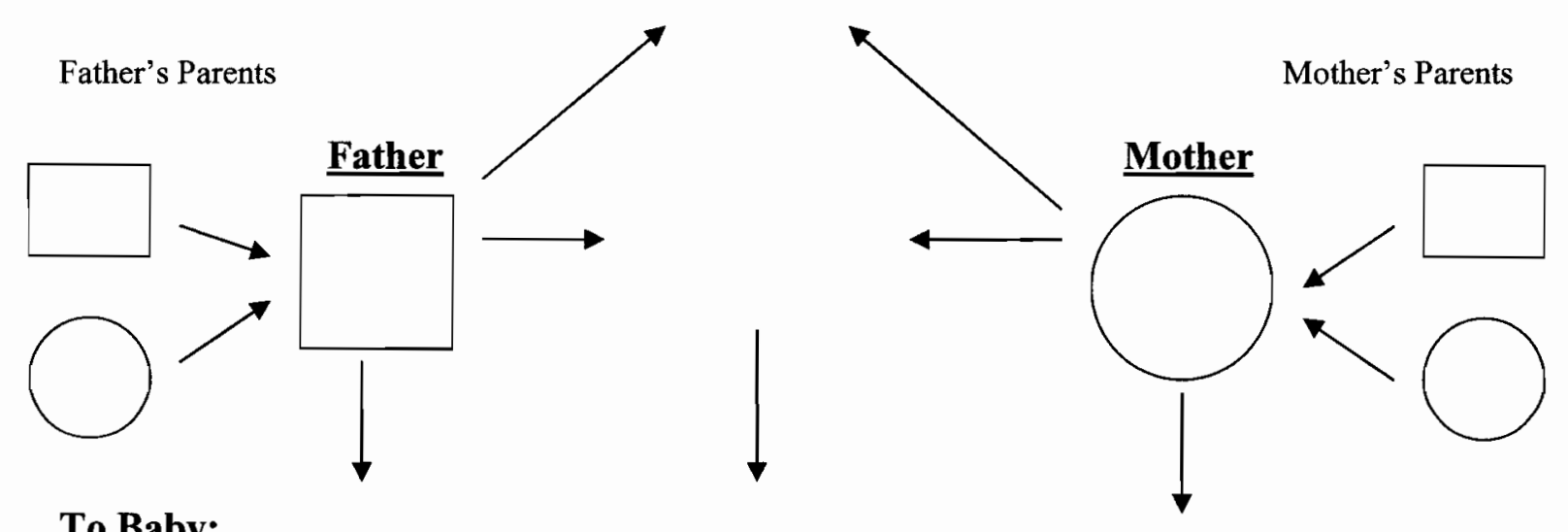

Sibling (Name \& Birthdate)

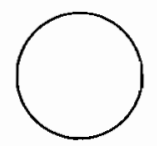

\section{DAYCARE}

Since:

Frequency: (hrs/day;

days/week):

Languages spoken : 
LANGUAGE BREAKDOWN OF EVERYONE WHO INTERACTS REGULARLY

WITH THE BABY (ex, parents, grandparents, siblings, babysitter, playmates,

friends of parents..)

Are there other people living in your home?

YES / NO Include them below

\begin{tabular}{|l|c|c|c|}
\hline Who & Day of Week & Lang Spoken \& \% Breakdown & \# Hrs/day \\
\hline Mom & M-F & & \\
\hline & S-S & & \\
\hline Dad & M-F & & \\
\hline & S-S & & \\
\hline & & & \\
\hline & & & \\
\hline & & & \\
\hline & & & \\
\hline & & & \\
\hline
\end{tabular}

Are these percentages different on vacations?

YES NO

If yes, have these vacations occurred since your child was born?

Give frequency, duration, and language breakdown percentages:

\section{LANGUAGE ENVIRONMENT}

In what language do you watch/listen to tv/radio? (give frequency)

TV/Movies :

Radio : 
If someone walks into your house on a typical day, what languages would they most likely hear the family speaking?

If you had to guess, what language would you say your baby's first words will be in?

PARENTS OVERALL ESTIMATE OF LANGUAGE ENVIRONMENT

\begin{tabular}{|l|c|}
\hline \multicolumn{1}{|c|}{ Language } & $\%$ \\
\hline English & \\
\hline French & \\
\hline & \\
\hline
\end{tabular}

\section{FINAL DETAILS}

Has your child ever been treated for ear infections? If yes, how many times?

Does your child have any colds or ear infections todav?

Which CLSC is closest to your house?

May we contact you again if we have another study?

Do you know any other parents that would be interested in having their child participate in our study 


\section{Appendix C \\ Passages Used to Create Stimuli}

\section{ENGLISH PASSAGES}

\section{PASSAGE 1}

The young boy got up quite early in order to watch the sunrise. This supermarket had to close due to economic problems. The committee will meet this afternoon for a special debate. Having a big car is not something I would recommend in this city. Mothers usually leave the maternity unit two days after giving birth.

\section{PASSAGE 2}

The next local elections will take place during the winter. Some more money will be needed to make this project succeed. Artists have always been attracted by the life in the capital. Your welcome speech will be delivered without the press officer's agreement. The latest events have caused an outcry in the international community.

\section{PASSAGE 3}

The local train left the station more than five minutes ago. The first flowers have bloomed due to the exceptional warmth of March. Trade unions have lost a lot of their influence during the past ten years. The green parties unexpectedly gained strong support from middle class people. This is the first time an international exhibition takes place in this town.

\section{PASSAGE 4}

In this case, the easiest solution seems to appeal to the high court. The last concert given at the opera was a tremendous success. They didn't hear the good news until last week on their visit to their friends. This year's Chinese delegation was not nearly as impressive as last year's. In spite of technical progress, predicting the weather is still very difficult 


\section{PASSAGE 5}

The art gallery in this street was opened only last week. In this famous coffee shop you will eat the best donuts in town. Most European banks close extremely early on Friday afternoons. The government is planning a reform of the educational program. The recent rainfall has caused very severe damage in the higher valleys.

\section{PASSAGE 6}

A hurricane was announced this afternoon on the TV. This rugby season promises to be a very exciting one. Science has acquired an important place in western society. The rebuilding of the city started the very first day after the earthquake. It is getting very easy nowadays to find a place in a nursery school.

\section{PASSAGE 7}

My grand-parent's neighbour is the most charming person I know. Nobody noticed when the children slipped away just after dinner. The library is opened every day from eight A.M. to six P.M. The city council has decided to renovate the medieval center. Seven paintings of great value have recently been stolen from the museum

\section{PASSAGE 8}

The parents quietly crossed the dark room and approached the boy's bed. Finding a job is difficult in the present economic climate. There is an important market twice a week on the main square of the village. The woman over there is an eminent specialist in plastic surgery. Most of the supporters of the football club had to travel for an entire day. 


\section{FRENCH PASSAGES}

\section{PASSAGE I}

Le gentil petit singe est triste parce qu'il n'a rien pour jouer. Heureusement, un gentil garçon arrive et lui donne un gros ballon rouge. Maintenant, le petit singe est content et il n'oublie pas de remercier le garçon. Elle a sorti ses plus belles fripes pour aller acheter des concombres. François a reçu un ornithorynque pour son anniversaire.

\section{PASSAGE 2}

Le parc n'est pas loin de la maison et ça me convient bien. Kim doit choisir entre le chandail couleur pizza et la blouse soupe minestrone. Lorsque le médecin part en vacances, on ne tombe pas malade. Je fais le tour des parfumeries pour collecter des échantillons gratuits. J'amène mon coussin et ma doudou au cinéma du quartier.

\section{PASSAGE 3}

Je suis arrivée tard a la réunion des retardataires anonymes. Il ne mange pas de jambon car ça lui rappelle les bras de sa grosse tante. Pète et répète sont sur un bateau et pète tombe dans la rivière. La pollution me rentre par les narines quand il fait chaud comme ça. Ils annoncent trente degrés a l'ombre pour demain dans l'après-midi.

\section{PASSAGE 4}

Un acarien est venu me faire des menaces après que j'ai passé l'aspirateur. L'acarien solitaire s'ennuie de ses copains et me le fait sentir. Ma clavicule me pique lorsque le Big Ben sonne dix-neuf heures à Londres. Le ciel vert annonce de fortes précipitations de chlorophylle. Aussitôt que j'en aurai fini avec ma photosynthèse, je serai a toi.

\section{PASSAGE 5}

Il semblerait que sa relation avec son escargot va de mal en pis. Le pis de cette vache est tacheté de bleu et fait un bruit de crécelle. Ses mots lui transpercèrent le coeur comme 
une fourchette attaque une tranche de salami. Bébé est parti a la discothèque, mais reviendra a temps pour son biberon. Gigi traversera les égouts les plus puants pour gagner son coeur.

\section{PASSAGE 6}

Si je manque d'air ça sera parce que tu en inspires plus qu'il n'en faut. Marc s'est étouffé avec un ressort du matelas cuit sur le feu. Les manufacturiers renient l'identité du bas en lui imposant un jumeau. Une fois que le mélangeur est mis en marche, on se cache sous la table. Les monarques sont très occupés a bailler quarante heures par semaine.

\section{PASSAGE 7}

Si je ne dis pas non ça ne me laisse pas d'autre option que de dire oui. En attendant l'ouragan, je compte les vents de la vente au détail. Elle souhaite extraire l'intrus de son cerveau occupé depuis des mois. Sans son café deux laits un sucre, la tasse se sent étrangement vide. Les cheveux se coupent avec des ciseaux tenus par des mains ayant des doigts.

\section{PASSAGE 8}

Maxime pense tirer le maximum de profit de sa vente de garage. Les journées sont longues et les nuits sont courtes de l'autre côté de la mer. J'aime les sandwich aux bananes et beurre d'arachides croquant léger. Michèle cherche son chat siamois depuis trois semaines et quatre jours. Pendant ce temps, les souris font la fête a longueur de journée. 


\section{JAPAINESE PASSAGES}

\section{PASSAGE I}

Shussango sooki ni taiinsuru keekooga tsuyomatta. Tokurei wa kaino sanseinashini wa mitomerarenai. Jikai no kaikaku no taishoo wa gakkookyooiku no naiyoodesu. Keekaku no jitsugen niwa shikin ga kanari hitsuyoodeshoo. Kodomo o kooritsukoo ni susumaseru nowa muzukashikunai.

\section{PASSAGE 2}

Monku wa shihainin ni iuno a tettoribayai. Saikin no jiken do sekai no yoron wa konranshiteira.. Hinode o mirutame ni sonoko wa hayaku kishooshita.

Chuusankaikyuunaibu do kankyohogoha ga seiryoku o nobashita. Ryooshin wa mono oto o tatezu ni kodomo no soba ni chikazuita.

\section{PASSAGE 3}

Oono shigo ni machi no saiken ga hajimatta. Haru no koozui de zuibun ookina higaiga deta. Koocha demo nominagara koko do matasete morauyo. Kotoshi no nihondaihyoodan wa kyonenyori ninzuu ga sukunai. Daitoshi no seikatsu wa tasuu no geijutsuka o hikitsuketa.

\section{PASSAGE 4}

Kesa no rajiode taifuukeihoo ga hatsureisareta. Guusuuno hini wa kono hiroba ni miseya ga deru. Kusuriya no kamisan wa moosugu kaimononi deru. Keikanwa yoogishano fuuteini nita shooni no mikaketa. Konokeeki no jootainomama dewa shokusagashi wa taihenda.

\section{PASSAGE 5}

Bankokuhakurankai wa sakunen kasaisareeta. Kochira no kata wa keiseigeka no senmonka desu. Boku wa baiorin no keiko o kazoekirenaikurai yasunda. Kokono 
shokudoo wa eiseijoo no mondai do heisasareta. Shitookyoku ga rekishikuiki no saikaihatsu ni chakushushita.

PASSAGE 6

Konshuu mo terebibangumi o mirujikan ga nai. Tsugino chihoosenkyo wa kondo no harugoro deshoo. Kookvooko otsuukikan no seibiwa doomitemo fujuubunua. Dokoka tooku do yakiimoya no fuenone ga natteiruyooda. Oozeino kyakunomae de tabako o suuno wa yametahoo ga yoi.

\section{PASSAGE 7}

Noomin no sonchoo ni taisuru fuman ga tamatta. Kaikakusuishinha ga kenchoomae de demokooshinshita. Moo gofun ijoo mae ni tokkyuu wa hoomu ni tsukimashitayo. Sobo no sumai no gokinjo wa yoi hitotachi bakaridesu. Doo gijutsu ga siiinposhitemo tenkiyohoo wa tekichuushinai.

\section{PASSAGE 8}

Konopanya no keiki wa konokaiwai do hyoobanda. Tsugi no gekijooshiizun wa totemo kyoomibukaidaroo. Moosugu rinjikokkaino kaiki ga hajimaruhazuda. Kokosuunen de roodoodantai no eikyooryoku tza teikashita. Amerikajin ga gaikokujin dato kangae tara kookaisuruzo. 


\section{Appendix D}

\section{Stimulus Ordering}

Sequence of Language Presentation for Each Order (both groups)

$\begin{array}{cccccc}\text { Order 1 } & \text { Order 2 } & \text { Order 3 } & \text { Order 4 } & \text { Order 5 } & \text { Order 6 } \\ \text { E } & \text { E } & \text { F } & \text { F } & \text { J } & \text { J } \\ \text { F } & \text { J } & \text { E } & \text { J } & \text { E } & \text { F } \\ \text { J } & \text { F } & \text { J } & \text { E } & \text { F } & \text { E } \\ \text { F } & \text { J } & \text { E } & \text { J } & \text { E } & \text { F } \\ \text { E } & \text { E } & \text { F } & \text { F } & \text { J } & \text { J } \\ \text { J } & \text { F } & \text { J } & \text { E } & \text { F } & \text { E } \\ \text { F } & \text { J } & \text { E } & \text { J } & \text { E } & \text { F } \\ \text { J } & \text { F } & \text { J } & \text { E } & \text { F } & \text { E } \\ \text { E } & \text { E } & \text { F } & \text { F } & \text { J } & \text { J } \\ \text { J } & \text { F } & \text { J } & \text { E } & \text { F } & \text { E } \\ \text { F } & \text { J } & \text { E } & \text { J } & \text { E } & \text { F } \\ \text { E } & \text { E } & \text { F } & \text { F } & \text { J } & \text { J }\end{array}$

$\mathrm{E}=$ English, $\mathrm{F}=$ French, $\mathrm{J}=\mathrm{J}$ apanese 


$\begin{array}{cccccc}\text { Group 1: Sequence of Specific Stimuli for Group 1 } & \\ \text { Order 1 } & \text { Order } 2 & \text { Order 3 } & \text { Order 4 } & \text { Order } 5 & \text { Order } 6 \\ \text { Eng 1-1 } & \text { Eng 2-3 } & \text { Fr 6-6 } & \text { Fr 5-3 } & \text { Jap 4-5 } & \text { Jap 3-3 } \\ \text { Fr 3-4 } & \text { Jap 4-5 } & \text { Eng 3-8 } & \text { Jap 1-1 } & \text { Eng 2-3 } & \text { Fr 5-3 } \\ \text { Jap 1-1 } & \text { Fr 3-4 } & \text { Jap 3-3 } & \text { Eng 1-1 } & \text { Fr 6-6 } & \text { Eng 3-8 } \\ \text { Fr 5-3 } & \text { Jap 3-3 } & \text { Eng 1-1 } & \text { Jap 4-5 } & \text { Eng 3-8 } & \text { Fr 3-4 } \\ \text { Eng 2-3 } & \text { Eng 1-1 } & \text { Fr 5-3 } & \text { Fr 6-6 } & \text { Jap 1-1 } & \text { Jap 1-1 } \\ \text { Jap 3-3 } & \text { Fr 6-6 } & \text { Jap 4-5 } & \text { Eng 3-8 } & \text { Fr 3-4 } & \text { Eng 2-3 } \\ \text { Fr 6-6 } & \text { Jap 1-1 } & \text { Eng 2-3 } & \text { Jap 3-3 } & \text { Eng 1-1 } & \text { Fr 6-6 } \\ \text { Jap 4-5 } & \text { Fr 5-3 } & \text { Jap 1-1 } & \text { Eng 2-3 } & \text { Fr 5-3 } & \text { Eng 1-1 } \\ \text { Eng 3-8 } & \text { Eng 3-8 } & \text { Fr 3-4 } & \text { Fr 3-4 } & \text { Jap 3-3 } & \text { Jap 4-5 } \\ \text { Jap 4-6 } & \text { Fr 5-2 } & \text { Jap 4-6 } & \text { Eng 1-5 } & \text { Fr 5-2 } & \text { Eng 1-5 } \\ \text { Fr 5-2 } & \text { Jap 4-6 } & \text { Eng 1-5 } & \text { Jap 4-6 } & \text { Eng 1-5 } & \text { Fr 5-2 } \\ \text { Eng 1-5 } & \text { Eng 1-5 } & \text { Fr 5-2 } & \text { Fr 5-2 } & \text { Jap 4-6 } & \text { Jap 4-6 }\end{array}$

The first number represents speaker number, and the second number represents their passage number. Thus English 2-3 is English speaker number 2 reciting passage number 3. 
Group 2: Sequence of Specific Stimuli for Group 2

$\begin{array}{cccccc}\text { Order 1 } & \text { Order 2 } & \text { Order 3 } & \text { Order 4 } & \text { Order 5 } & \text { Order 6 } \\ \text { Eng 1-5 } & \text { Eng 2-4 } & \text { Fr 6-8 } & \text { Fr 5-2 } & \text { Jap 4-6 } & \text { Jap 3-8 } \\ \text { Fr 3-7 } & \text { Jap 4-6 } & \text { Eng 3-7 } & \text { Jap 1-4 } & \text { Eng 2-4 } & \text { Fr 5-2 } \\ \text { Jap 1-4 } & \text { Fr 3-7 } & \text { Jap 3-8 } & \text { Eng 1-5 } & \text { Fr 6-8 } & \text { Eng 3-7 } \\ \text { Fr 5-2 } & \text { Jap 3-8 } & \text { Eng 1-5 } & \text { Jap 4-6 } & \text { Eng 3-7 } & \text { Fr 3-7 } \\ \text { Eng 2-4 } & \text { Eng 1-5 } & \text { Fr 5-2 } & \text { Fr 6-8 } & \text { Jap 1-4 } & \text { Jap 1-4 } \\ \text { Jap 3-8 } & \text { Fr 6-8 } & \text { Jap 4-6 } & \text { Eng 3-7 } & \text { Fr 3-7 } & \text { Eng 2-4 } \\ \text { Fr 6-8 } & \text { Jap 1-4 } & \text { Eng 2-4 } & \text { Jap 3-8 } & \text { Eng 1-5 } & \text { Fr 6-8 } \\ \text { Jap 4-6 } & \text { Fr 5-2 } & \text { Jap 1-4 } & \text { Eng 2-4 } & \text { Fr 5-2 } & \text { Eng 1-5 } \\ \text { Eng 3-7 } & \text { Eng 3-7 } & \text { Fr 3-7 } & \text { Fr 3-7 } & \text { Jap 3-8 } & \text { Jap 4-6 } \\ \text { Jap 1-1 } & \text { Fr 6-6 } & \text { Jap 1-1 } & \text { Eng 2-3 } & \text { Fr 6-6 } & \text { Eng 2-3 } \\ \text { Fr 6-6 } & \text { Jap 1-1 } & \text { Eng 2-3 } & \text { Jap 1-1 } & \text { Eng 2-3 } & \text { Fr 6-6 } \\ \text { Eng 2-3 } & \text { Eng 2-3 } & \text { Fr 6-6 } & \text { Fr 6-6 } & \text { Jap 1-1 } & \text { Jap 1-1 }\end{array}$


Table 1

Summary of Monolingual Discrimination Studies

\begin{tabular}{|c|c|c|c|c|c|c|c|}
\hline \multirow[b]{2}{*}{ Researcher } & \multirow[b]{2}{*}{ Age } & \multirow[b]{2}{*}{$\begin{array}{l}\text { Infant } \\
\text { Lang. }\end{array}$} & \multirow[b]{2}{*}{$\begin{array}{l}\text { Procedure \& } \\
\text { Stimuli }\end{array}$} & \multicolumn{2}{|c|}{$\begin{array}{l}\text { Stimuli: Interclass } \\
\text { Languages }\end{array}$} & \multicolumn{2}{|c|}{$\begin{array}{l}\text { Stimuli: Intraclass } \\
\text { Languages }\end{array}$} \\
\hline & & & & $\begin{array}{l}\text { Native vs } \\
\text { Foreign }\end{array}$ & $\begin{array}{l}\text { Foreign vs } \\
\text { Foreign }\end{array}$ & $\begin{array}{l}\text { Native vs } \\
\text { Foreign }\end{array}$ & $\begin{array}{l}\text { Foreign vs } \\
\text { Foreign }\end{array}$ \\
\hline \multirow[t]{3}{*}{$\begin{array}{l}\text { Mehler et al. } \\
\text { (1988);Mehler } \\
\text { \& Christophe } \\
\text { (1994) }\end{array}$} & $\begin{array}{l}\text { New- } \\
\text { born }\end{array}$ & $\begin{array}{l}\text { French } \\
\text { babies }\end{array}$ & $\begin{array}{l}\text { HAS, ADS, } 1 \\
\text { bilingual talker }\end{array}$ & $\begin{array}{l}\text { Fr vs. } \\
\text { Rus. }\end{array}$ & $\begin{array}{l}\text { Eng vs. } \\
\text { Ital. }\end{array}$ & & \\
\hline & & $\begin{array}{l}\text { French } \\
\text { babies }\end{array}$ & $\begin{array}{l}\text { reversed Fr \& } \\
\text { Rus stimuli }\end{array}$ & $\begin{array}{l}{ }^{*} F r v s . \\
\text { Rus.* }\end{array}$ & & & \\
\hline & & $\begin{array}{l}\text { French } \\
\text { babies }\end{array}$ & LPF stimuli & $\begin{array}{l}\text { Fr vs } \\
\text { Rus. }\end{array}$ & & & \\
\hline \multirow[t]{2}{*}{$\begin{array}{l}\text { Nazzi et al. } \\
\text { (1998) }\end{array}$} & $\begin{array}{l}\text { New- } \\
\text { born }\end{array}$ & $\begin{array}{l}\text { French } \\
\text { babies }\end{array}$ & $\begin{array}{l}\text { Habit, } 4 \text { native } \\
\text { speakers/lang, } \\
\text { ADS, LPF }\end{array}$ & & Jap vs Eng & & $\begin{array}{l}{ }^{*} \text { Eng vs } \\
\text { Dutch* }\end{array}$ \\
\hline & & $\begin{array}{l}\text { French } \\
\text { babies }\end{array}$ & & & $\begin{array}{l}\text { Eng+Dut } \\
\text { vs Span+ } \\
\text { Ital }\end{array}$ & & $\begin{array}{l}{ }^{*} \text { Eng+ } \\
\text { Ital vs Dut+ } \\
\text { Span* }\end{array}$ \\
\hline $\begin{array}{l}\text { Mehler et al. } \\
\text { (1988) }\end{array}$ & $\begin{array}{l}2- \\
\text { month }\end{array}$ & $\begin{array}{l}\text { English } \\
\text { infants }\end{array}$ & $\begin{array}{l}\text { Visual fixation } \\
\text { procedure, ADS, } \\
1 \text { biling. talker }\end{array}$ & $\begin{array}{l}\text { Eng vs. } \\
\text { Ital. }\end{array}$ & $\begin{array}{l}{ }^{*} R u s . v s \\
F r *\end{array}$ & & \\
\hline
\end{tabular}

Eng=discriminated; ${ }^{*} E n g^{*}=$ Not discriminated; $<E n g>=$ marginally significant; HPP=headturn preference procedure; HAS=high-amplitude sucking procedure; Habit= habituation procedure; $\mathrm{ADS}=$ =adult-directed speech; IDS=infant-directed -speech; LPF=low-pass filtered 


\begin{tabular}{|c|c|c|c|c|c|c|c|}
\hline $\begin{array}{l}\text { Christophe \& } \\
\text { Morton (1988) }\end{array}$ & $\begin{array}{l}2- \\
\text { month }\end{array}$ & $\begin{array}{l}\text { English } \\
\text { infants }\end{array}$ & $\begin{array}{l}\text { HAS, ADS, } 4 \\
\text { speakers/lang }\end{array}$ & $\begin{array}{l}\text { Eng. vs. } \\
\text { Jap. }\end{array}$ & $\begin{array}{l}* F r v s . \\
\text { Jap. }{ }^{*}\end{array}$ & & \\
\hline & & $\begin{array}{l}\text { English } \\
\text { infants }\end{array}$ & & & $\begin{array}{l}<\text { Dutch vs. } \\
\text { Jap }>\end{array}$ & & \\
\hline & & $\begin{array}{l}\text { English } \\
\text { infants }\end{array}$ & & $\begin{array}{l}<\text { Dutch } \\
\text { vs. Eng. }>\end{array}$ & & & \\
\hline $\begin{array}{l}\text { Bahrick \& } \\
\text { Pickens (1988) }\end{array}$ & $\begin{array}{l}5- \\
\text { month }\end{array}$ & $\begin{array}{l}\text { English } \\
\text { infants }\end{array}$ & $\begin{array}{l}\text { visual fixation } \\
\text { procedure, ADS, } \\
1 \text { biling. talker }\end{array}$ & $\begin{array}{l}\text { Eng vs } \\
\text { Span }\end{array}$ & & & \\
\hline \multirow[t]{2}{*}{$\begin{array}{l}\text { Bosch \& } \\
\text { Sebastián- } \\
\text { Gallés } \\
(1997 ; 2001)\end{array}$} & $\begin{array}{l}\text { 4- } \\
\text { month }\end{array}$ & $\begin{array}{l}\text { Spanish } \\
\text { babies }\end{array}$ & $\begin{array}{l}\text { reaction time, } \\
\text { familiarization- } \\
\text { pref. proc., IDS, } \\
\text { unfiltered \& LPF, } \\
1 \text { speaker }\end{array}$ & $\begin{array}{l}\text { Span vs } \\
\text { Eng }\end{array}$ & & $\begin{array}{l}\text { Span vs } \\
\text { Catalan }\end{array}$ & \\
\hline & & $\begin{array}{l}\text { Catalan } \\
\text { babies }\end{array}$ & & $\begin{array}{l}\text { Catalan } \\
\text { vs Eng }\end{array}$ & & $\begin{array}{l}\text { Span vs } \\
\text { Catalan }\end{array}$ & \\
\hline $\begin{array}{l}\text { Nazzi et al. } \\
(2000)\end{array}$ & $\begin{array}{l}5- \\
\text { month }\end{array}$ & $\begin{array}{l}\text { Americ } \\
\text { an } \\
\text { English } \\
\text { babies }\end{array}$ & $\begin{array}{l}\text { HPP, ADS, } 4 \\
\text { speakers of each } \\
\text { language }\end{array}$ & $\begin{array}{l}\text { BrEng vs } \\
\text { Jap }\end{array}$ & Ital vs Jap & $\begin{array}{l}\text { BrEng vs } \\
\text { AmEng; } \\
\text { BrEng } \\
\text { vs Dutch }\end{array}$ & $\begin{array}{l}\text { *Ital vs } \\
\text { Span*; } \\
\text { *Dutch vs } \\
\text { German* }\end{array}$ \\
\hline
\end{tabular}

Eng=discriminated; ${ }^{*} E n g *=$ Not discriminated; $<E n g>=$ marginally significant; HPP=headturn preference procedure; HAS=high-amplitude sucking procedure; Habit= habituation procedure; $\mathrm{ADS}=$ adult-directed speech; IDS=infant-directed -speech; LPF=low-pass filtered 
Table 2

Summary of Monolingual Preference Studies

\begin{tabular}{|c|c|c|c|c|c|c|c|}
\hline \multirow[b]{2}{*}{ Researchers } & \multirow[b]{2}{*}{ Age } & \multirow[b]{2}{*}{$\begin{array}{l}\text { Infant } \\
\text { Lang. }\end{array}$} & \multirow[b]{2}{*}{$\begin{array}{l}\text { Procedure \& } \\
\text { Stimuli }\end{array}$} & \multicolumn{2}{|c|}{$\begin{array}{l}\text { Stimuli: Interclass } \\
\text { Languages }\end{array}$} & \multicolumn{2}{|c|}{$\begin{array}{l}\text { Stimuli: Intraclass } \\
\text { Languages }\end{array}$} \\
\hline & & & & $\begin{array}{l}\text { Native vs } \\
\text { Foreign }\end{array}$ & $\begin{array}{l}\text { Foreign vs } \\
\text { Foreign }\end{array}$ & $\begin{array}{l}\text { Native vs } \\
\text { Foreign }\end{array}$ & $\begin{array}{l}\text { Foreign vs } \\
\text { Foreign }\end{array}$ \\
\hline $\begin{array}{l}\text { Moon et al. } \\
\text { (1993) }\end{array}$ & $\begin{array}{l}\text { New- } \\
\text { borns }\end{array}$ & $\begin{array}{l}\text { English } \\
\text { babies }\end{array}$ & $\begin{array}{l}\text { HAS, ADS, } 8 \\
\text { speakers/lang. (1 } \\
\text { child listens to } 1 \\
\text { speaker/lang) }\end{array}$ & $\begin{array}{l}\text { \#Eng vs } \\
\text { Span. }\end{array}$ & & & \\
\hline & & $\begin{array}{l}\text { Spanish } \\
\text { babies }\end{array}$ & & $\begin{array}{l}\text { Eng vs. } \\
\text { \#Span }\end{array}$ & & & \\
\hline $\begin{array}{l}\text { Hayashi et al. } \\
(2001)\end{array}$ & $\begin{array}{l}4-6 \\
\text { month }\end{array}$ & $\begin{array}{l}\text { Japanese } \\
\text { infants }\end{array}$ & $\begin{array}{l}\text { HPP, IDS, } 1 \\
\text { bilingual speaker }\end{array}$ & $\begin{array}{l}\text { Eng vs. } \\
\text { Jap }\end{array}$ & & & \\
\hline $\begin{array}{l}\text { Hayashi et al. } \\
(2001)\end{array}$ & $\begin{array}{l}7-14 \\
\text { month }\end{array}$ & $\begin{array}{l}\text { Japanese } \\
\text { infants }\end{array}$ & $\begin{array}{l}\text { HPP, IDS, } 1 \\
\text { bilingual speaker }\end{array}$ & $\begin{array}{l}\text { Eng vs. } \\
\text { \#Jap }\end{array}$ & & & \\
\hline
\end{tabular}

\#Eng=preferred language; $\mathrm{HPP}=$ headturn preference procedure; $\mathrm{HAS}=$ high-amplitude sucking procedure;

ADS=adult-directed speech; IDS=infant-directed speech . 
Table 3

Summary of Bilingual Discrimination Studies

\begin{tabular}{|c|c|c|c|c|c|c|c|c|}
\hline \multirow[b]{2}{*}{ Researcher } & \multirow[b]{2}{*}{ Age } & \multirow[b]{2}{*}{$\begin{array}{l}\text { Infant } \\
\text { Lang. }\end{array}$} & \multirow[b]{2}{*}{$\begin{array}{l}\text { Procedure \& } \\
\text { Stimuli }\end{array}$} & \multicolumn{2}{|c|}{$\begin{array}{l}\text { Stimuli: Interclass } \\
\text { Languages }\end{array}$} & \multicolumn{3}{|c|}{$\begin{array}{l}\text { Stimuli: Intraclass } \\
\text { Languages }\end{array}$} \\
\hline & & & & $\begin{array}{l}\text { Native vs } \\
\text { Foreign }\end{array}$ & $\begin{array}{l}\text { Foreign } \\
\text { vs } \\
\text { Foreign }\end{array}$ & $\begin{array}{l}\text { Native } \\
\text { vs. } \\
\text { Native }\end{array}$ & $\begin{array}{l}\text { Native } \\
\text { vs } \\
\text { Foreign }\end{array}$ & $\begin{array}{l}\text { Foreign } \\
\text { vs } \\
\text { Foreign }\end{array}$ \\
\hline $\begin{array}{l}\text { Bosch et al } \\
(1997)\end{array}$ & $\begin{array}{l}4 \\
\text { mo }\end{array}$ & $\begin{array}{l}\text { Spanish/ } \\
\text { Catalan }\end{array}$ & $\begin{array}{l}\text { reaction time } \\
\text { measure, } 1 \\
\text { quadralingual } \\
\text { speaker, IDS }\end{array}$ & $\begin{array}{l}\text { Span vs } \\
\text { Eng; } \\
\text { Catalan vs. } \\
\text { Eng }\end{array}$ & & $\begin{array}{l}\text { *Span } \\
\text { vs. } \\
\text { Catalan } \\
\text { *l }\end{array}$ & $\begin{array}{l}\text { Span } \\
\text { vs. } \\
\text { Italian; } \\
\text { Catalan } \\
\text { vs. Ital. }\end{array}$ & \\
\hline $\begin{array}{l}\text { Bosch et al } \\
(2001)\end{array}$ & $\begin{array}{l}4 \\
\text { mo }\end{array}$ & $\begin{array}{l}\text { Spanish/ } \\
\text { Catalan }\end{array}$ & $\begin{array}{l}\text { familiarization } \\
\text { preference } \\
\text { procedure, IDS, } 1 \\
\text { quadralingual } \\
\text { speaker }\end{array}$ & & & $\begin{array}{l}\text { Span } \\
\text { vs. } \\
\text { Catalan }\end{array}$ & & \\
\hline
\end{tabular}

Eng=discriminated; ${ }^{*} E n g^{*}=$ Not discriminated; IDS $=$ infant-directed speech.

${ }^{1}$ Due to the design of this experiment it is not clear if this result represents a lack of discrimination ability or a lack of preference among the bilingual infants. 